\title{
Strategic Identity Signaling in Heterogeneous Networks
}

\author{
Tamara van der Does ${ }^{1,}$, Mirta Galesic ${ }^{1}$, Zackary Dunivin ${ }^{2,3}$, and \\ Paul E. Smaldino ${ }^{4}$ \\ ${ }^{1}$ Santa Fe Institute, 1399 Hyde Park Road, Santa Fe NM 87501, USA. \\ ${ }^{2}$ Center for Complex Networks and Systems Research, Luddy School of Informatics, Computer \\ Science, and Engineering, Indiana University, 919 E 10th St, Bloomington, IN 47408 USA \\ ${ }^{3}$ Department of Sociology, Indiana University, 1020 E Kirkwood Ave, Bloomington, IN 47405 USA \\ ${ }^{4}$ Department of Cognitive and Information Sciences, University of California, Merced, 5200 Lake \\ Rd, Merced, CA 95343 USA \\ ${ }^{*}$ Corresponding author: tamara.vdd@gmail.com
}

\begin{abstract}
Individuals often signal identity information to facilitate assortment with partners who are likely to share norms, values, and goals. However, individuals may also be incentivized to encrypt their identity signals to avoid detection by dissimilar receivers, particularly when such detection is costly. Using mathematical modeling, this idea has previously been formalized into a theory of covert signaling. In this paper, we provide the first empirical test of the theory of covert signaling in the context of political identity signaling surrounding the 2020 U.S. presidential elections. To identify likely covert and overt signals on Twitter, we use novel methods relying on differences in detection between ingroup and outgroup receivers. We strengthen our experimental predictions with a new mathematical model and examine the usage of selected covert and overt tweets in a behavioral experiment. We find that participants strategically adjust their signaling behavior in response to the political constitution of their audiences. These results support our predictions and point to opportunities for further theoretical development. Our findings have implications for our understanding of political communication, social identity, pragmatics, hate speech, and the maintenance of cooperation in diverse populations.
\end{abstract}

Significance statement: Much of online conversation today consists of signaling one's political identity. Although many signals are obvious to everyone, others are covert, recognizable to one's ingroup while obscured from the outgroup. This type of covert identity signaling is critical for collaborations in a diverse society but measuring covert signals has been difficult, slowing down theoretical development. We develop a novel method to detect covert and overt signals in tweets posted before the 2020 U.S. presidential election, and use a behavioral experiment to test predictions of a mathematical theory of covert signaling. Our results show that covert political signaling is more common when the perceived audience is politically diverse and open doors to a better understanding of communication in politically polarized societies.

Keywords: covert signaling; political identity; pragmatics; networks; Twitter

Classification: Social Sciences - Psychological and Cognitive Sciences 


\section{Introduction}

Individuals constantly emit signals of their identity, consciously and unconsciously, informing others about the sort of person they are. Identity signals are any components of communication that inform receivers of the signaler's membership (or non-membership) in a subset of individuals (Donath, 1999; Berger, 2008; Smaldino, 2019b). Such subsets can reflect strong social boundaries, such as "Republican" or "Democrat" in the U.S., or reflect subtler intragroup variations, such as differences among Democrats regarding government regulations. In large, multicultural nations like the U.S., identities like Republican or Democrat can serve to organize like-minded communities or coalitions (Huddy et al., 2015; Mason, 2018; Klein, 2020; Osmundsen et al., 2021). Although the specific style of communication may vary with cultural context (Moya and Boyd, 2015), identity signaling serves a key social function by enabling individuals to rapidly characterize others as similar or dissimilar (McElreath et al., 2003; Berger, 2008; Smaldino, 2019b). Finding similar others has many proximate psychological benefits, such as better mental health (Cohen and Wills, 1985) and the security that results from a stronger sense of group identity (Merolla et al., 2012; Serpe and Stryker, 1987). Our emphasis here is on the role of identity signaling to facilitate social assortment: preferentially interacting with similar individuals and reaping the benefits of coordinating on norms, goals, and values (Barth, 1969; Berger, 2008; Brewer, 1991; McElreath et al., 2003; Smaldino, 2019b; Wimmer, 2013).

Identity signaling is especially important in vast and diverse social communities, where little can be assumed about strangers in the absence of identity information. This type of scenario is made all the more common in the digital age (Donath, 2014). In recent years, online social media has both expanded the pool of potential partners and enabled easier formation of communities across traditional social and geographic boundaries. This presents new challenges and opportunities for signalers to successfully find niche communities (Plant, 2004; Nagle, 2017). On the one hand, large online communities have arisen dedicated to worldviews that are otherwise rare in most local communities. An individual expressing a viewpoint that is rare in their locality can nevertheless become part of a flourishing, geographically dilute collective. On the other hand, online signaling also carries new risks that come from expanding one's audience far beyond one's local social network, sometimes without the signaler's knowledge (e.g., Ronson, 2015).

Given the social importance of political identity in the U.S. and other countries (Joireman, 2003; Mason, 2018), we expect much identity signaling to be about political views and related coalitional affiliations. Political views are often expressed on social media using obvious signals like slogans, partisan memes, and other declarations of partisanship. However, the U.S. is also highly polarized (Mason, 2018; Klein, 2020), and obvious political signals are not always advisable. Partisans often hold deeply negative feelings toward members of groups perceived as opposed or even simply different to their own (Abramowitz and Webster, 2016; Iyengar et al., 2012, 2019; Yang et al., 2021). Signaling one's political affiliation to outgroup members can therefore be costly, with costs ranging from the loss of social standing or relationship opportunities to the loss of an employment (Copeland, 2019) or even becoming the victim of violence (Keegan, 2018). For example, Van Duyn (2018) documents a group of anti-Trump women in rural Texas who met in secret to discuss politics because they feared negative consequences for their business or marriages if their views became known. Exactly 
who is considered a member of one's outgroup also varies over time and context. In the context of political identities, debates during U.S. presidential primaries tend to be between members of the same political party, and so a perceived outgroup may be co-partisans that support different candidates or policy goals. During national presidential elections, crosspartisan differences become more salient. In both cases, the assortative benefits of overt identity signaling must be weighed against the potential costs of being identified by outgroup individuals in situations where identification has consequences.

Overt, unambiguous signals of identity are useful when individuals can sufficiently benefit from their role in supporting positive assortment-preferentially interacting with similar others. A wide literature on social tags and ethnic markers has documented and modeled the utility and likely emergence of such signals for this purpose (Barth, 1969; Nettle and Dunbar, 1997; McElreath et al., 2003; Hammond and Axelrod, 2006; Castro and Toro, 2007; Waring et al., 2017). The benefits of overt identity signaling, however, must sufficiently outweigh any risks that come from alienating others or revealing oneself to be misaligned with their interests. If those risks and their associated costs are high enough, we should expect cultural or psychological processes (such as cultural evolution or strategic decision making) to favor subtler signaling strategies that encode information in such a way that it is detectable only by those who share relevant worldviews.

We refer to identity signals that are accurately received by their intended audience but obscured when received by others as covert signals (Smaldino et al., 2018; Smaldino, 2019b; Smaldino and Turner, 2021). Covert signals allow individuals to reap at least some benefit from being identified by similar others when possible, while simultaneously avoiding the costs associated with detection by dissimilar others. Covert signals work because communication often contains multiple, simultaneous layers of meaning, which are not all equally apparent to all receivers. A receiver's background knowledge and perception of context affects whether and how those layers will be revealed (Grice, 1975; Searle, 1975; Sperber and Wilson, 1986; Clark and Schaefer, 1987). Individuals should therefore adjust their patterns of communication based not only on their intended audience, but also on the likely third parties that will perceive those communications (Clark and Carlson, 1982; Clark and Schaefer, 1987; Loury, 1994). Loury (1994, p. 448) captures the essence of the idea: "If the significance of some words as signals of belief is known only to 'insiders,' their use in public allows the speaker to convey a reassuring message to some listener - 'I share your values' - without alarming the others." A well-documented example is the routine remarks made by former U.S. president George W. Bush concerning his opposition to the 1857 Dred Scott Supreme Court decision. While it might seem banal to oppose a judicial decision that upheld slavery, the mention was seen by many evangelical conservatives as morally analogous to the 1973 Roe v. Wade case that upheld the right to abortion, and so communicated to these audiences the president's commitment to overturning that decision (Kirkpatrick, 2004).

Recently, Smaldino and colleagues have developed a theory of covert signaling, using formal mathematical and agent-based models of cultural evolution to examine the circumstances under which overt or covert identity signaling strategies should be favored (Smaldino et al., 2018; Smaldino and Turner, 2021). The theory of covert signaling provides a formalism for identity signaling in the context of third-party receivers, and describes how signalers should communicate based on their likely audiences and the consequences for both successful and failed communication. The models derived from this theory make general predictions 
about strategies for identity signaling related to both the ability of individuals to preferentially assort with similar others and the costs of failing to assort accordingly. Covert signaling can achieve higher payoffs than overt signaling when individuals are likely to have interactions with dissimilar individuals and when those interactions incur high costs once the dissimilarity is revealed. The theory of covert signaling is consistent with a number of common signaling domains, including the use of humor as an encrypted signal of similarity (Flamson and Barrett, 2008; Flamson and Bryant, 2013), the use of fashion to subtly signal insider status (Berger and Ward, 2010), political dog whistles (López, 2015; Henderson and McCready, 2017), and signals used by LGBTQ + individuals (Fischer, 2015; Shelp, 2003) or political dissidents (Kuran, 1989, 1995; Boyer, 2018) to assort without detection. It is also consistent with the fact that signals of political identity need not be obviously political in nature, as reliable associations with certain products and activities may be used as heuristics to differentiate partisans (DellaPosta et al., 2015; Settle, 2018; Hiaeshutter-Rice et al., 2021).

It is likely that a great deal of online speech is covert, especially on social media platforms on which users can be personally identified, such as Twitter. Although other social media sites have more users than Twitter (Pew Research Center, 2021), Twitter is a particularly important forum for public discourse on current events, and as such is valuable for studying covert identity signals that are likely to be both relevant and visible to diverse audiences. For example, the strategy of "subtweeting" is well documented and refers to online communications that are interpretable only to individuals who have relevant information that is not provided in the communication itself (Marwick and boyd, 2014). As another example, a search for tweets containing the phrase "remember that scene" sent on November 9, 2016 (the day after Donald Trump was elected as U.S. president) returned a number of candidate covert tweets concerning feelings about the election results, many from users unhappy with the outcome (Figure 1). Each of these requires background knowledge about the cultural artifact (i.e., film) being referenced, as well as an understanding of recent political events as the relevant contextual backdrop for interpreting the analogy implied by those references. Our data was collected during an especially salient period for political identity signaling on Twitter: the 2020 COVID-19 pandemic, in which millions of people were restricted from gathering and communicating in person, making online engagement one of the principal ways to interact with other humans. Moreover, our tweets were collected and assessed in the wake of many high profile sociopolitical events in the U.S., including the Black Lives Matter protests following the murder of George Floyd, the confirmation of Supreme Court Justice Amy Coney Barrett, and the 2020 presidential election. Opinions on these events were often polarized, making expressions of those opinions into signals of political identity.

While they are likely to be common, covert signals are also inherently challenging to study empirically, because by definition they require insider knowledge to be detected. In this paper, we introduce a theoretically-motivated measurement of covertness, focusing on identity signals in the context of political speech online. Essentially, covertness was measured in terms of how people from ingroup and outgroup political groups perceived different tweets. On Twitter, cross-partisan followers are rare (Halberstam and Knight, 2016), and thus we focused on differences between co-partisan radicals and moderates. We downloaded tweets from politically engaged Twitter users with heterogeneous follower networks, thus increasing our chances to collect tweets with some covert political identity signaling according to the theory. Then, we asked ingroup and outgroup members to guess the political identity of the 


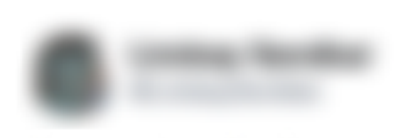

Remember that scene in LOTR where that old dude tries to burn his still-living son and the lil hobbit is like "NOOOO YOU CAN'T DO THIS!"

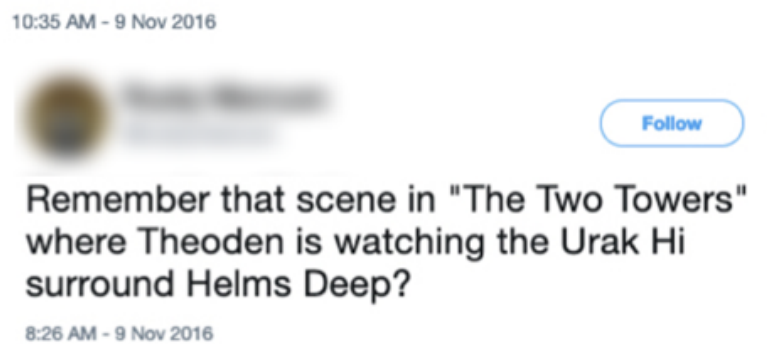

remember that scene

Follow

Remember that scene in Deliverance, what the hillbillies did to the city folk? I just thought of that right now for some reason. So weird.

12:05 AM - 9 Nov 2016

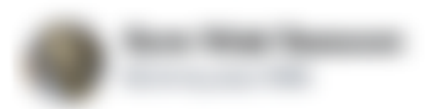

Follow

hey remember that scene in Titanic when the lights go out and everyone realizes nobody's going to rescue them?

10:29 AM - 9 Nov 2016

Figure 1: Potentially covert tweets related to the 2016 U.S. presidential election. To understand each tweet, the reader must be familiar with both the ingroup conversations about the relevant political events as well as the cultural artifacts being referenced.

tweet author and to report their affective responses to the tweet. Tweets were considered to be more likely to serve as covert identity signals if there was a large difference in responses of ingroup and outgroup raters.

Our paper constitutes the first direct empirical test of the theory of covert signaling. Based on this theory, we predict that covert signaling will be more prevalent among 1) individuals in more heterogeneous communities or individuals with minority status, and 2) individuals who face higher costs from being recognized as dissimilar. We derive a simple mathematical model of our experimental design, which yields more precise predictions concerning the relationships between covert signaling, the frequency of outgroup members in the audience, and the cost of being disliked. We test these predictions in a behavioral experiment in which participants select from a set of tweets that contain either overt or covert political signals to communicate with and be evaluated by an audience of varying partisanship. We compare signaling strategies when the outgroup audience consists of co-partisan members (more or less radical) and cross-partisan members (left or right). Although previous studies have also considered the use of covert or encrypted signals (Shelp, 2003; Flamson and Barrett, 2008, 2013; Berger and Ward, 2010), ours is the first to test predictions derived from a formal model with relatively unambiguous predictions and a clear scope of applicability (sensu Walker and Cohen, 1985). By doing so, we can show where the existing theory fits the real world and where we need to direct our future efforts to refine the theory.

\section{Methods}

To test our theoretical predictions, we designed an empirical pipeline that consisted of 1) selecting Twitter users who might be more likely to use covert or overt political speech and downloading their tweets, 2) rating a selection of tweets on different dimensions and marking a subset as more likely to be covert or overt, and 3) conducting a behavioral experiment with 
the selected covert and over tweets to test whether people indeed use them to communicate their political beliefs in theoretically predicted conditions. Figure 2 summarizes the overall process.

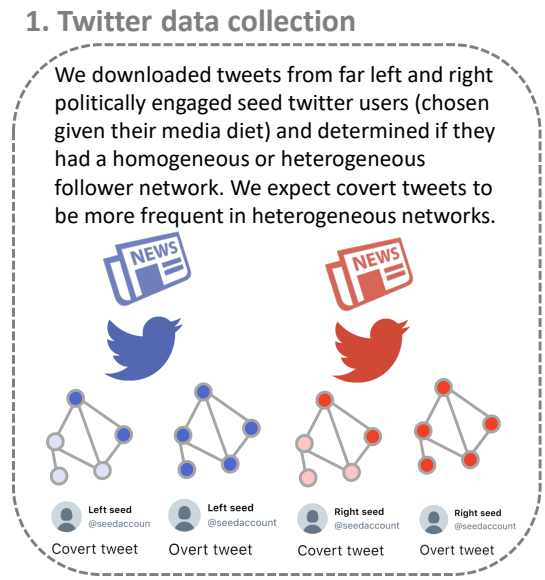

2. Rating and classification of tweets

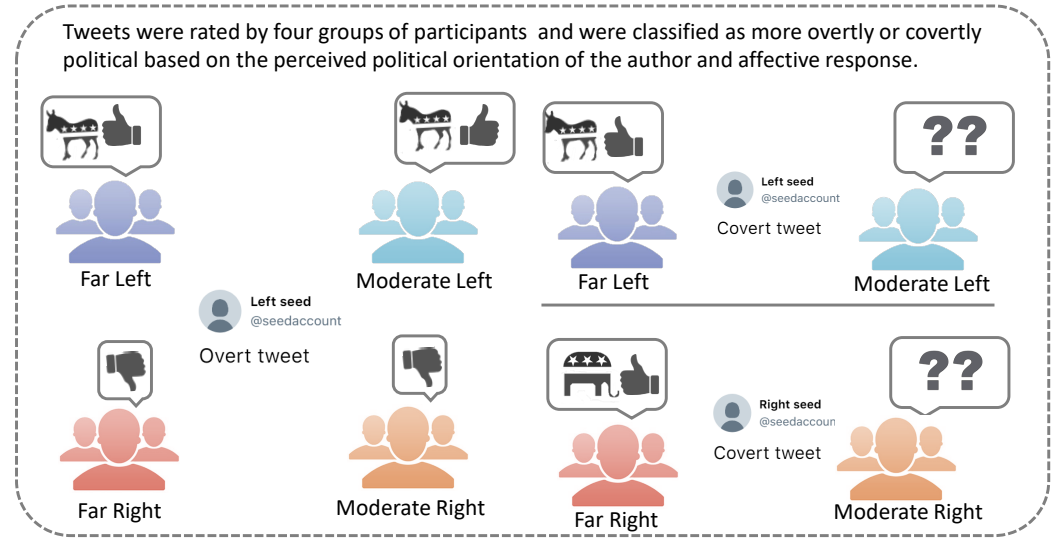

3. Behavioral experiment

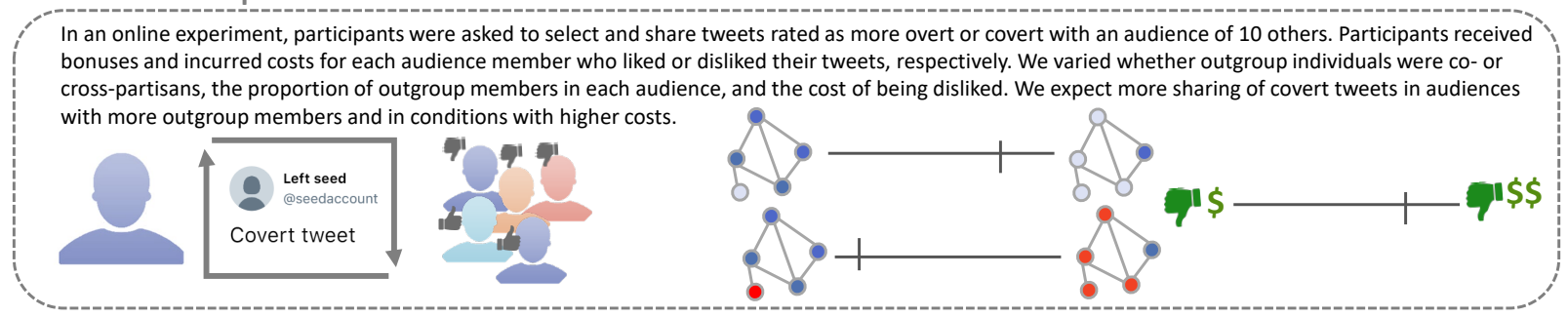

Figure 2: Empirical process to test the theory of covert signaling

\section{Twitter data collection}

We developed a novel process for selecting candidate tweets that would maximize the proportion of overt and covert political signals on both sides of the political spectrum (Figure 2 Panel 1). To download these tweets, we also chose a time frame that had intensified political discussions online: September 15th through October 12th 2020. Overall, our selection process was designed to both minimize the amount of work needed to rate all the tweets downloaded and maximize the potential number of covert and overt tweets to use in the behavioral experiment.

First, we selected seed Twitter accounts from a list of followers of eight news accounts representing far left and far right factions of the U.S. political landscape on Twitter (see Table S1 of the SI Appendix). These news accounts generally corresponded to the progressive left wing, more closely affiliated with the Democratic party, and the Trumpist or Tea Party right wing, more closely affiliated with the Republican Party. As Twitter's API limits the download of lists of followers, we randomly sampled 10,000 followers of each of the eight news accounts. Any account that had not tweeted four weeks prior to sampling was rejected and replaced through continued sampling. We were able to download the list of followers for 73,869 of these accounts (fewer than the 80,000 originally planned due to technical limitations). 
Second, we developed a schema for classifying the political orientation of each seed account based on their media diet as represented by the proportion of far left or right political news sources they followed. We identified highly "polarized" U.S.-based news outlets using data from mediabiasfactcheck.com and selected those whose Twitter accounts had at least 10,000 followers. This produced a set of 43 far left news accounts and 50 far right news accounts (see Table S1 in SI Appendix). While these sets of accounts might not represent a coherent political identity, they can still be combined to approximate the orientation and degree of political engagement of a single Twitter user. We downloaded the follower list for each of the news accounts and ranked far left/right seed accounts by the proportion of far left/right news accounts they followed from our list. We selected the top $20 \%$ of these seed accounts on the left and right, representing the most "engaged" accounts and thus more likely to use political identity signaling.

Third, we classified the networks of each of the engaged seed accounts as either politically homogeneous or heterogeneous. We considered different operationalizations of political heterogeneity. One potential operationalization of heterogeneity is the relative proportion of cross-partisans in one's follower network. However, we found that cross-partisan follower relationships (as identified by media diet) were rare, and embeddedness in a cross-partisan follower network was practically nonexistent. Instead, we operationalize homogeneity and heterogeneity in terms of the extent of engagement with co-partisan far left/right news accounts. Homogeneous follower networks are those that are about as engaged, or committed to strong partisanship, as their seed accounts, while heterogeneous follower networks are much less engaged than their seed accounts. Drawing on the theory of covert signaling, we expect seed accounts with heterogeneous networks to be less likely to overtly share their political identity than seed accounts with homogeneous networks.

Followers of our seed accounts were labeled as engaged if they followed at least as many news accounts as the 50th percentile of our initial pool of seed accounts (three for the left, four for the right), and as disengaged if they followed at most one far left/right news site. In order to have a pool of tweets with both many overt and covert tweets, we selected seed accounts that had the most homogeneous and heterogeneous networks. Specifically, we selected the top $20 \%$ of engaged seed accounts, ranked by the proportion of engaged followers in their networks, and labeled them as having "homogeneous networks" (as they were politically engaged themselves and had a high proportion of engaged followers). Then, we selected the top $20 \%$ of engaged seed accounts, ranked by the proportion of disengaged followers in their networks, and labeled them as having "heterogeneous networks" (as they were politically engaged themselves and had a high proportion of disengaged followers). We ended up with 1,834 far left accounts and 1,446 far right engaged accounts with either homogeneous or heterogeneous follower networks.

Fourth, we downloaded tweets from the resulting four groups of engaged seed accounts (far left/right with homogeneous/heterogeneous follower networks). Using the Twitter API we downloaded up to the maximum number of available tweets from each user $(3,200)$ in the four weeks leading up to the behavioral experiment. We filtered out tweets that would be difficult to understand for independent raters (see next section), removing tweets that were posted more than six weeks prior, were replies to other users, contained images or news article links, were not in English, or were too short (fewer than five words or 50 characters, unless they contained hashtags which tend to be high-content, contextualizing signals). To 
further improve legibility, we deleted all other links from tweets. Finally, we removed retweets to avoid duplicates. This procedure produced between 1,303 and 2,100 tweets for each of the four groups of seed accounts (far left/right with homogeneous/heterogeneous follower networks), for a total of 6,594 tweets. Of those, we randomly selected 1,303 or 1,304 tweets for each group, for a total of 5,215 tweets (originating from 1,409 seed accounts) to be rated and classified as covert or overt, as described in the following sections.

\section{Rating and classification of tweets}

To determine whether tweets downloaded in the previous section were overt or covert, we recruited human raters (Figure 2 Panel 2). To establish a pool of raters, we pre-selected individuals from Mechanical Turk whose political orientation was either far left, moderate left, moderate right, or far right and who had at least a minimum amount of political literacy. We determined their political leaning based on news diet, self-reported political identification, and views on radical political movements. Political literacy was determined using self-reports of frequency of following the news, a political quiz, and familiarity with news discussions on social media. We describe the participant selection process in detail in Section 2 of the SI Appendix. We invited from this pre-selected pool a sample of 2,695 raters. Of those, 1,992 raters responded ( $\mathrm{N}=483$ far left, 533 moderate left, 461 far right, and 515 moderate right).

We asked raters several questions about each tweet to determine the tweet's position on two dimensions: political orientation and affective response (see Questionnaire in Section 3 of the SI Appendix). For the political orientation dimension, raters were asked to estimate the perceived political orientation of the tweets' authors on a seven-point scale from extreme left to extreme right, or to answer "not political". For the affective response dimension, raters were asked two questions: to estimate how negatively they felt towards a tweet, and how offensive the tweet would be to people similar to themselves (from very offensive to not offensive). The two ratings were highly correlated $(r=.70)$ and were averaged in one summative scale. We pre-tested a third question on the offensiveness for other groups but excluded it given that it did not clearly reflect how the ingroup or outgroup reacted to the political signal.

Each rater received 50 randomly selected tweets, a number that according to our pretests one person could evaluate in 20 minutes, approximating the feasible duration for an online study (Galesic and Bosnjak, 2009). Of the 5,215 tweets selected as described in the previous step, we obtained ratings from at least three raters from each of the four political-leaning groups (far left, moderate left, moderate right, and far right) for 4,752 tweets. Each tweet was given four scores for the two dimensions, reflecting the average response of the four groups of raters (see Section 3 of the SI Appendix). To investigate inter-rater reliability, we fitted a random effects linear model to probe how much variation in the political leaning ratings could be attributed to individual raters. The multilevel regression model estimates random effects for tweet, rater, and partisanship of rater (our four groups). We used Shapley regression to decompose the explained variance (in this case, McFadden's pseudo-R2). The multilevel regression accounts for $50.0 \%$ of the total variance. Of this, $89.3 \%$ of the variance can be attributed to the tweets themselves. Raters account for $10.3 \%$ of the explained variance, which is just $5.12 \%$ of the total variance. Thus we conclude that while each rater 
saw a different subset of tweets and rating is somewhat noisy, inter-rater reliability was high.

We used a set of criteria (Table S6) drawing on the theoretical framework of Smaldino and colleagues (Smaldino et al., 2018; Smaldino and Turner, 2021) to use these scores to select covert and overt tweets. Under the assumption that partisans with extreme views were likely to be highly engaged and therefore more likely to be attuned to covert co-partisan political signals, we expected that extreme partisans would recognize covert signals as supporting a particular political side and would experience a strong affective response, while more moderate partisans would show no consistent response on these dimensions. In contrast, overt tweets should be recognized by most people as advocating a particular political side, and should be liked if they supported one's own political identity. Note that our assumption that extreme partisans are more likely to be attuned to covert co-partisan political signals deviates from standard conceptions of ingroup and outgroup signaling. However, in a highly politicized environment such as the contemporary United States, extreme partisans are often motivated primarily by their opposition to the outgroup (Abramowitz and McCoy, 2019; Iyengar et al., 2019; Osmundsen et al., 2021), and are therefore highly attuned to signals of outgroup membership and unlikely to be fooled by covert signals. In contrast, moderate partisans are less likely to have detailed insider knowledge of the ingroup signals used by cross-partisans.

Accordingly, we marked tweets as potentially covert if they satisfied the following five theory-based criteria (Figure 2 Panel 2 and Table S6 in the SI Appendix for details): large co-partisan difference in tweets' perceived political orientation and affective scores, neutral ratings of political orientation given by moderates, neutral or positive affective score by moderates, and political content recognized by far co-partisan raters. We marked tweets as potentially overt if they satisfied the following four theory-based criteria (see Table S6 for details): small cross-partisan difference in tweets' political orientation score, large difference in cross-partisan and small difference in co-partisan affective score, and political content recognized by all raters. We set up percentile cutoffs to obtain approximately 30 tweets that had the highest probability to represent each of the four categories - overt left (33), covert right (29), overt left (55), and overt right tweets (37) - for a total of 154 automatically preselected tweets. From these, we selected 20 tweets (the number that was feasible time-wise for our our behavioral experiment) in each of the four categories using independent evaluations of overall covertness/overtness by each of the four authors, followed by a joint discussion. Two right-leaning tweets were erroneously included as covert tweets for the behavioral experiment and were subsequently recoded as neither covert nor overt for the analysis.

In Section 3 of the SI Appendix, we show that the average group-level response for covert and overt tweets across dimensions match our criteria. Furthermore, we examine in the SI Appendix Section 4 whether covert and overt tweets appear in more homogeneous or heterogeneous Twitter networks and find supportive results, i.e. a greater fraction of political tweets from users with heterogeneous networks were covert than was true for homogeneous networks (SI Appendix Figure S5). Together, these show our ratings and criteria carry useful information related to political signaling and suggest that covert and overt tweets should be perceived differently by participants in our behavioral experiment. While our methods were designed to select the most likely covert and overt tweets in our sample, we refer to these tweets as "overt" and "covert" in our results for simplicity. 


\section{Behavioral experiment}

We used the tweets selected as overt and covert political signals in the previous section to conduct an experimental study testing our theoretical predictions in a controlled setting. We designed a behavioral experiment to test two predictions derived from the theory of covert signaling: (1) Individuals should use more covert signaling when in more heterogeneous groups or when they are in the minority, and (2) individuals should use more covert signaling when the costs of being recognized as dissimilar are higher.

We selected a subset of 240 participants from the pool of raters described above who were screened as being far left/right in their political views and 240 who were more moderate; with equal number of participants with left and right political identities in far and moderate groups. In the first part of the experiment, participants were asked if they liked, disliked, or were neutral towards each of the 80 left and right-leaning tweets selected for this stage. In the second part of the experiment, participants were asked to select and share tweets to an audience of ten other participants. Each participant saw a randomly sorted list of 40 only left- or right-leaning tweets, matching their own political orientation, split between covert and overt messages. Participants were paid a baseline of $\$ 3.40$ and were given a bonus for each audience member who liked the majority of the tweets they shared and charged a cost for each audience member who disliked the majority of their tweets. The instructions to the participants are shown in Figure S6 and Figure S7 of the SI Appendix.

Participants were randomly split in two experimental groups: one having a strictly copartisan audience (in which audience members were identified as either extreme or moderate co-partisans) and one having a partly cross-partisan audience (in which audience members were identified simply as either co- or cross-partisans). Each group participated in eight successive rounds, randomly ordered to vary two within-subject factors: 1) the number of people in the audience with political leanings different than their own (one, four, six, or nine people in the outgroup, either more radical or mainstream for participants with a co-partisan audience or from the opposing political side for participants with a cross-partisan audience) and 2) the cost of dislikes, either a low-cost condition where the cost of dislikes (0.5 cents) was half of the bonus for likes (1 cent) or a high-cost condition where the cost of dislikes was the same as the bonus for likes (both 1 cent). Bonuses were calculated based on the actual likes and dislikes recorded from participants in the first part of the experiment.

\section{Results}

\section{Audience response to overt and covert signals}

Audience members in the behavioral experiment liked and disliked covert and overt tweets in line with our definitions of covert and overt signaling. A the same time, as might be expected from a comparison between theoretical modeling and empirical reality, participant behavior was more nuanced than our original theoretical assumptions. Overall, as shown in Figure 3, all groups tended to like tweets from their own side of the political spectrum (co-partisans) and tended to dislike tweets from the opposite side (cross-partisans). There were also marked differences between moderates and radicals. Moderates on average liked fewer tweets from co-partisans and disliked fewer tweets from cross-partisans compared to 
radicals. Covert tweets were liked less often by co-partisans and disliked less often by crosspartisans compared to overt tweets. Unlike simplified assumptions in prior theoretical models (Smaldino et al., 2018; Smaldino and Turner, 2021), we find here that using covert tweets only decreases, but does not completely prevent, dislikes from the outgroup. Regardless, the best strategy for maximizing likes and reducing dislikes remains consistent with the expectations from the theory of covert signaling: sharing more covert tweets as the size of the outgroup increases and when the cost of dislikes is high. With this information in hand, we derive more precise predictions for the advantage of covert compared to overt signaling in a mathematical model.
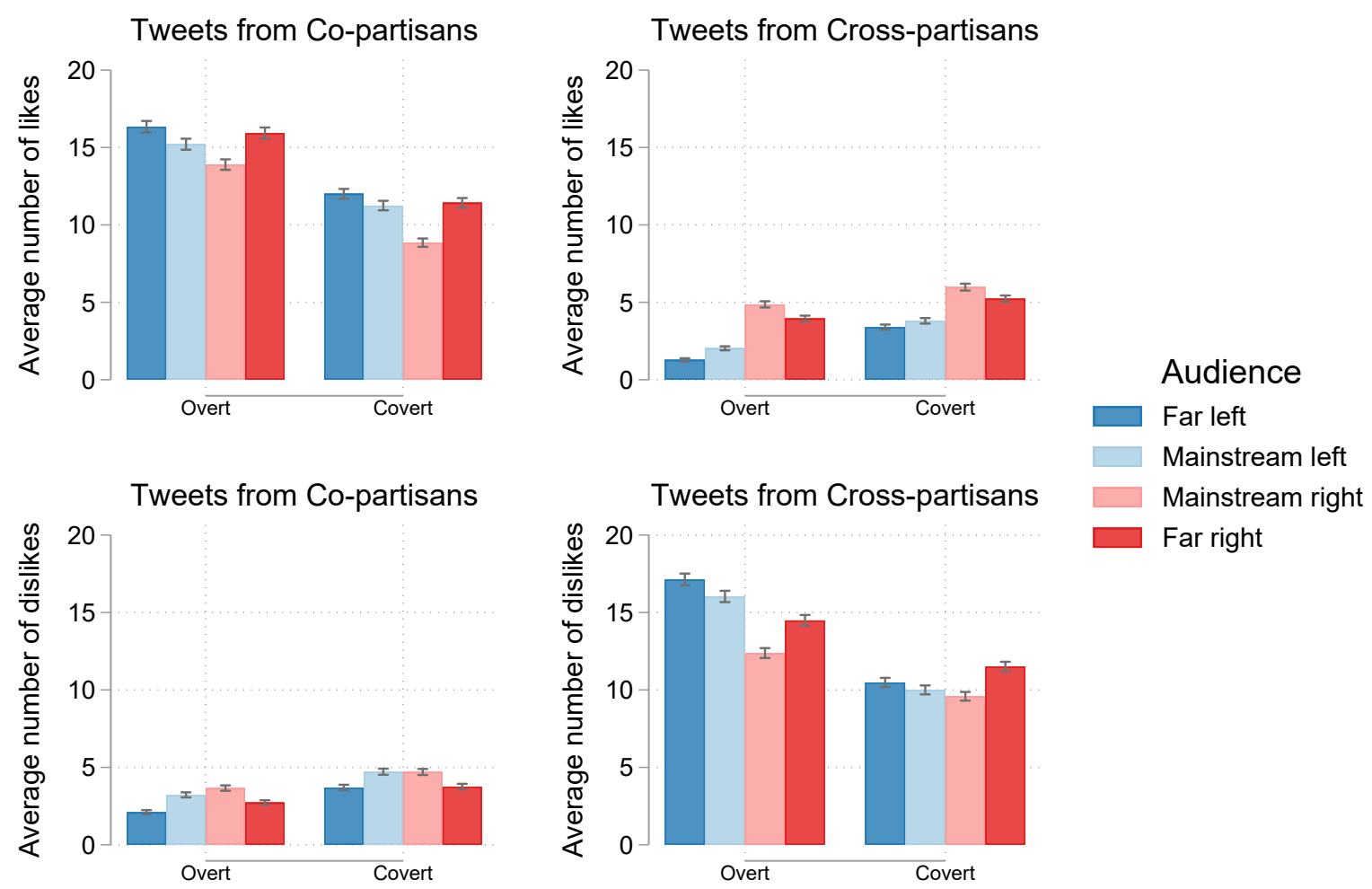

Figure 3: Average number of overt and covert tweets that were liked by co- and crosspartisan audience members $(\mathrm{N}=481)$. Error bars represent the standard error around the mean assuming a Poisson distribution. 


\section{Mathematical predictions for signaling strategies with varying out- group sizes and costs}

In order to better interpret the results of our experiment, we developed a simple mathematical model in which we consider the relative expected payoffs to pure strategies of covert or overt signaling. The model allows us to make predictions under the assumption of rational behavior, though the source of that rationality could stem from either individual strategizing or population-level selection on optimal signaling strategies (c.f. Mesoudi, 2011).

In an audience of size $N$, a proportion $d$ will be members of the outgroup and the rest will be members of the ingroup. We assume that overt signals are received (that is, the identity signal denoting similarity or dissimilarity is perceived) by all audience members with probability $R$, and that covert signals are received by ingroup members with a probability $r_{I}<R$ and are perceived by outgroup members with probability $r_{O}<r_{I}$. Audience members who perceive similarity will like the signal, conferring a benefit $b$ on the signaler, while audience members who perceive dissimilarity will dislike the signal, imposing a cost $c$ on the signaler. These costs and benefits are added to the baseline benefit for participation, $w_{0}$.

The expected payoff to an overt signaler is therefore:

$$
W_{O}=w_{0}+R[(1-d) N b-d N c]
$$

Similarly, the expected payoff to a covert signaler is:

$$
W_{C}=w_{0}+r_{I}(1-d) N b-r_{O} d N c
$$

Covert signalers avoid some of the cost of being disliked, but also receive fewer liking benefits. The relative advantage of covert signaling depends heavily on the proportion of outgroup members in the audience, as well as the signal efficiency of both overt and covert signals.

We calibrated the model to our experiment by setting $N=10, b=1$, and allowing the cost to vary so $c=\{0.5,1\}$, reflecting the low and high-cost conditions, respectively. Our values for receiving probabilities $\left(R=0.8, r_{I}=0.6, r_{O}=0.5\right)$ were estimated from our experimental data (Figure 3). Note that this differs from the simplified assumption in prior models (Smaldino et al., 2018; Smaldino and Turner, 2021) that $r_{O}=0$, indicating the importance of testing these models empirically.

Figure 4 shows the relative payoff advantage to covert signaling (in cents) for experimental values. The figure shows that covert signaling is favored when the audience is composed primarily of outgroup members, and overt signaling is favored otherwise. Although we also see differences between the cost conditions, these manifest primarily with higher proportions of outgroup members, and the advantage to covert signaling under high-cost is quite small relative to the difference between small and large values of $d$. We therefore expect a smaller effect of cost compared to outgroup size in our experiment. It is also worth noting that this simplified model focuses on pure strategies, predicting a total switch from overt to covert signaling as the audience reaches a critical threshold of outgroup members. In reality, experimental subjects often played mixed strategies, indicating that real world signaling is much more fraught with uncertainty than the model indicates. 


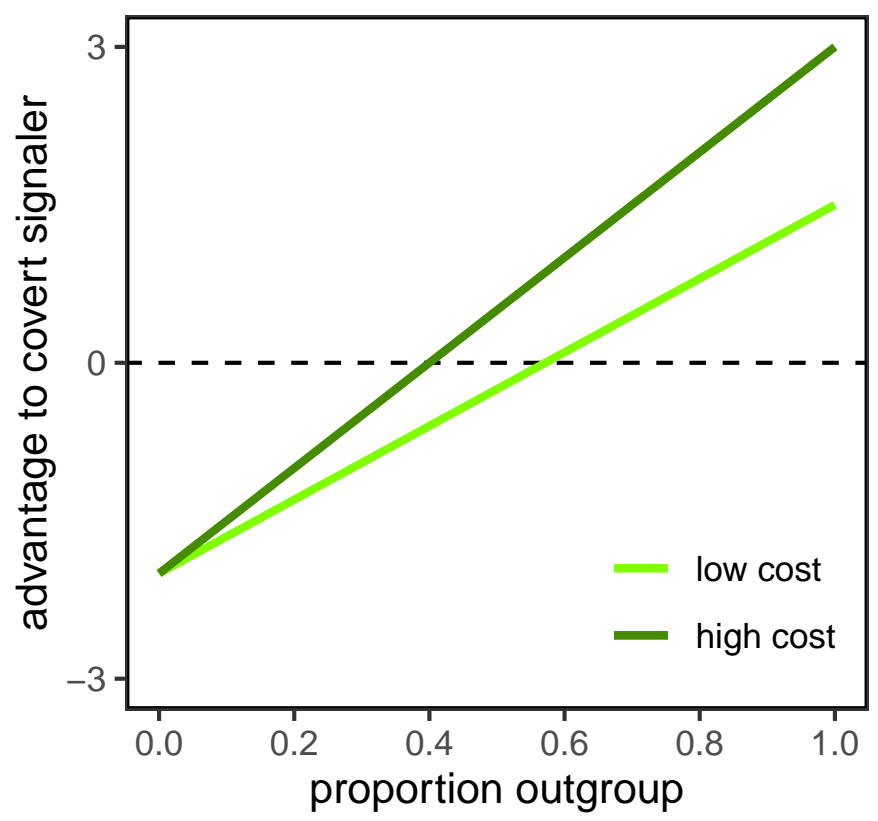

Figure 4: Difference in expected payoff between overt and covert signaling as a function of the outgroup proportion of the audience, $d$. Here $N=10, b=1, R=0.8, r_{I}=0.6$, $r_{O}=0.5$. The costs are $c=1$ in the high-cost condition (dark green) and $c=0.5$ in the low-cost condition (light green).

\section{Empirical signaling strategies with varying outgroup sizes and costs}

The theory of covert signaling (Smaldino et al., 2018; Smaldino and Turner, 2021) predicts that covert signaling will be more prevalent among 1) individuals in more heterogeneous communities or with minority status, and 2) individuals who face higher costs from being recognized as dissimilar. The mathematical model we present above further predicts that in our particular experiment the the first effect will be larger than the second one. For our first prediction, we explored conceptualizations of the outgroup as either cross-partisans (e.g. left-leaning vs. right-leaning) or co-partisans (e.g., far left vs. moderate left).

To formally compare the effect of outgroup size (one or nine audience members out of ten) and cost of dislikes ( 0.5 or 1 cent) within individuals and between individuals, we estimated a mixed-effects Poisson model on the count of tweets shared per round with each outgroup experimental condition nested within individuals and random intercepts for each individual. We used a Poisson distribution to approximate the distribution of number of covert tweets shared and total number of tweets shared in our sample (SI Appendix Figure S9). In these models, we controlled for the participants' age, gender, race, education, and political group (descriptive statistics in SI Appendix Table S8). Figure 5 presents the average predictive margins for the number of total and covert tweets shared across outgroup sizes and costs. To create these predictive margins, we averaged the predicted number of tweets derived from our full statistical model (see Section 8 in the SI Appendix) across the distribution of gender, age, race, and education in our sample. Our estimates and confidence intervals therefore represent the effects for a population similar to our sample: politically engaged and social 
Number of covert tweets shared controlling for total shared

(a) Co-partisan audience $(\mathrm{N}=238)$

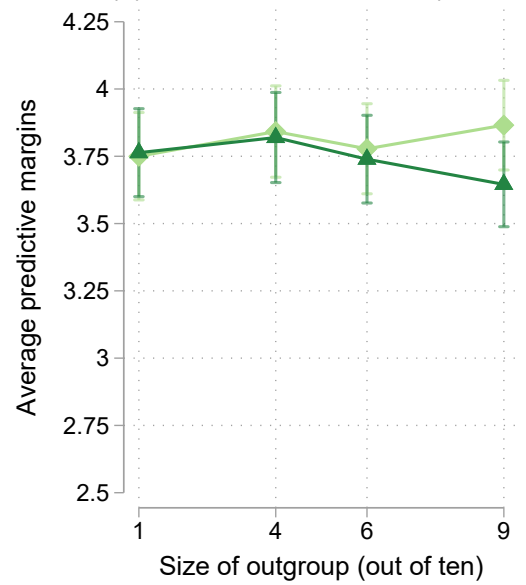

(b) Cross-partisan audience $(\mathrm{N}=243)$

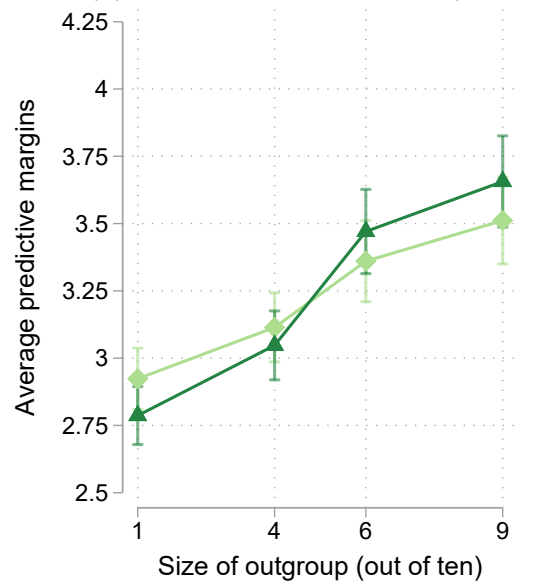

Total number of tweets shared per round

(c) Co-partisan audience $(\mathrm{N}=238)$

(d) Cross-partisan audience $(\mathrm{N}=243)$
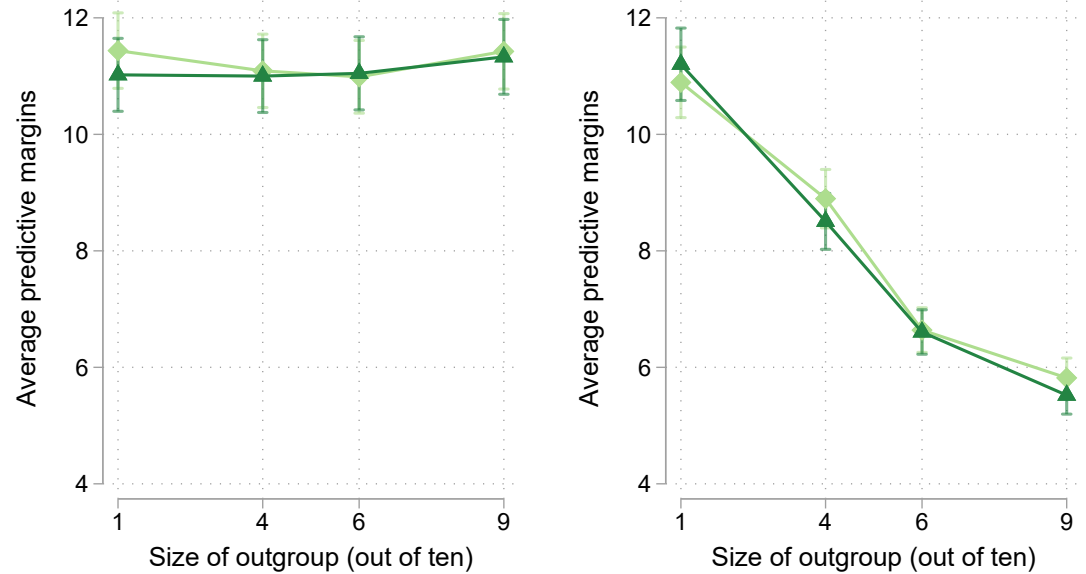

Low-cost

High-cost

Figure 5: Average predictive margins for the total number of covert (a, b) and total (c, d) tweets shared by cost of dislikes across different outgroup sizes, $N=478$. The outgroup is either composed of cross-partisans (a,c) or co-partisans (b,d). Estimates from mixedeffects Poisson models, averaging predicted number of tweets shared across sample values for number of tweets shared, political leaning, age, gender, race, and education. Error bars represent standard errors around the mean. 
media literate Americans across the political spectrum (see SI Appendix Section 2 for our selection criteria). The resulting Average Marginal Effect (AME) of outgroup size on the use of covert tweets represents the difference between the average predictive margins between two specific values of outgroup size.

In line with our first theoretical prediction, we found that participants used more covert signaling as the number of outgroup individuals in the audience increased, as long as the outgroup was conceptualized as cross-partisans (Figure 5b). As the size of the cross-partisan audience increased from one outgroup member to nine, participants tended to use a higher proportion of covert tweets $\left(A M E_{\text {outgroup }}=0.722,95 \% C I=[0.462,0.982]\right)$. Even though being the extreme minority was associated with the highest proportion of covert tweets shared, there was also a significant difference between situations with audiences of four outgroup members and six outgroup members, in the high-cost condition $\left(A M E_{\text {outgroup }}=\right.$ $0.434,95 \% C I=[0.088,0.780])$. In the SI Appendix, we show that participants who changed their signaling strategy in line with theoretical predictions in the cross-partisan condition did receive higher bonuses at the end of the experiment (Figure S8).

There was no effect of outgroup size on the use of covert tweets when the outgroup consisted entirely of members of the same political party, holding either more moderate or more radical views (Figure 5a, Bayes Factor for null, $B F_{01}=e^{\Delta B I C_{10} / 2}=43.32$ ). In the context of the behavioral experiment, the difference between radicals and moderates within the same party was likely not salient enough to lead to changing strategies across network contexts, and only the cross-partisan condition followed the expectation of the covert signaling identity. This also reflects the fact that the covert and overt tweets used in the experiment were mostly related to cross-partisan disputes. Relatedly, the lack of a co-partisan effect may also reflect increased perceptions of cross-partisans as members of an "outgroup" compared with co-partisans of varying intensity, particularly during the time the experiment was run.

We did not find strong support for our second theoretical prediction regarding a difference in signaling strategy based on costs. When presented with a higher cost of dislikes in the context of cross-partisan audiences, participants used slightly fewer covert tweets when there was only one outgroup member in the audience. They similarly used slightly more covert tweets when there were nine outgroup members in the audience compared to lower cost conditions. However, these differences are not significant and there is overall not a strong effect of cost on the relationship between outgroup size and signaling $\left(B F_{01}=16.68\right)$. The lack of effect likely reflects the small difference in possible payouts between cost conditionsonly 20 cents - which may not have been sufficient to induce a strong behavioral change. This is somewhat consistent with the mathematical model of our experiment, described above, which predicted a small effect of cost.

Participants also became more discerning as the size of the outgroup increased. As seen in the cross-partisan condition in Figure $5 \mathrm{~d}$, as the size of the outgroup increased from one to nine, participants shared fewer tweets overall $\left(A M E_{\text {outgroup }}=-5.38,95 \% C I=\right.$ $[-6.04,-4.72])$. This was true in both the high- and low-cost conditions. However, given the results from Figure 5b, we know that this reduction in the total number of tweets shared was mostly due to reducing the number of overt tweets shared, and retaining a few covert tweets. In additional analyses, we explored whether participants' signaling strategies varied by political literacy, familiarity with Twitter, and demographics (age, gender, race, 


\section{Co-partisan}
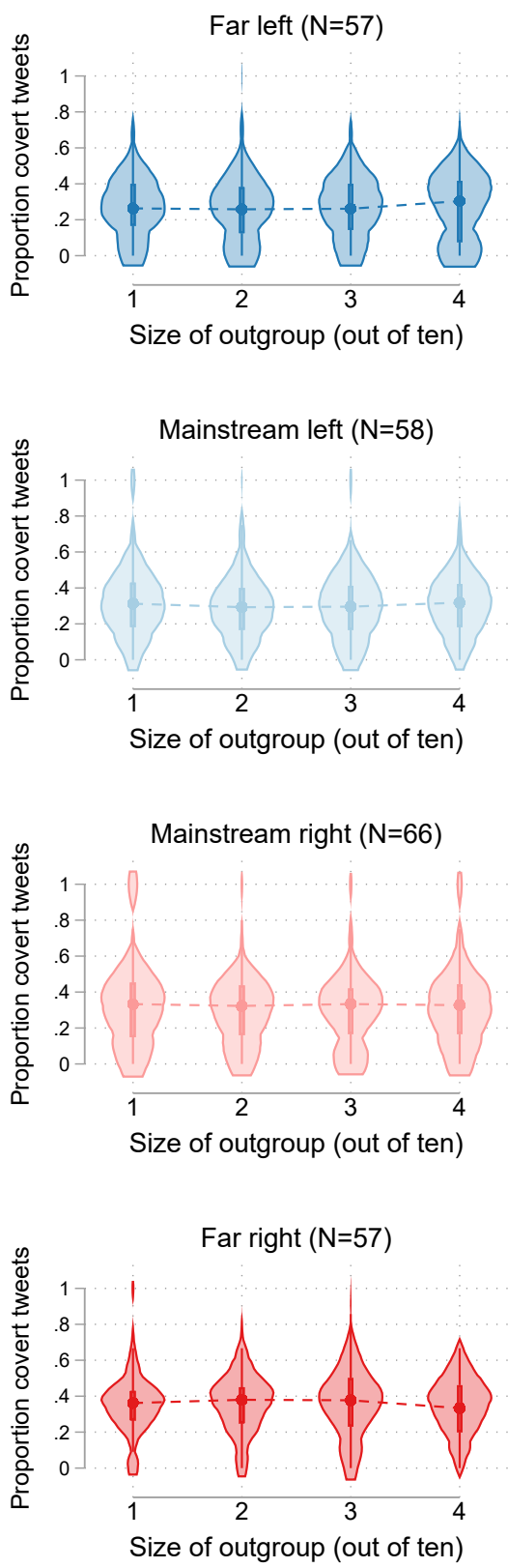

Cross-partisan
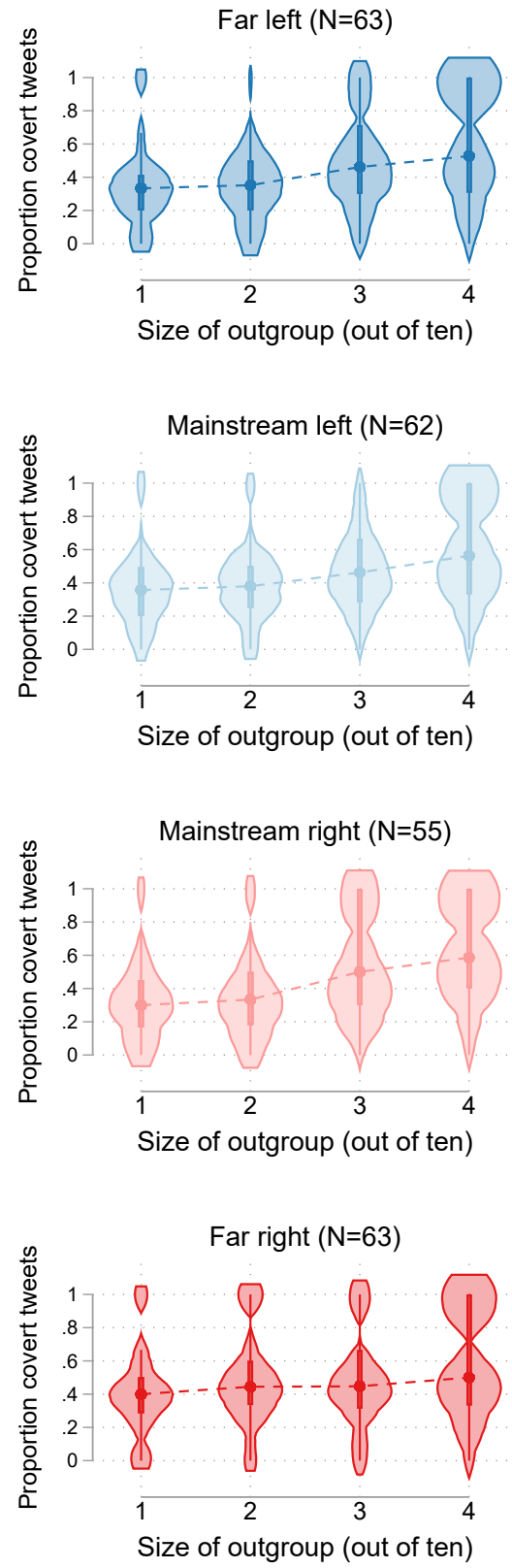

Figure 6: Distribution of participants' proportion of covert tweets shared in each round across each cost and outgroup size conditions, comparing participants who shared tweets to a co-partisan audience and cross-partisan audience and separating participants who were determined to be far left, mainstream left, mainstream right, and far right, $\mathrm{N}=481$. Violin plots include a marker for the median of the data, a box for the interquartile range, and spikes extending to the upper- and lower-adjacent values, all overlaid by a density plot using the Epanechnikov kernel function. 
and education), finding no reliable differences between groups. We do find some subtle differences in signaling behavior across the four political groups studied, as described next.

The main results hold descriptively across all four political groups (Figure 6): as the proportion of the audience consisting of outgroup (cross-partisan) individuals increased, participants shared relatively more covert tweets (right column), with no consistent differences observed for purely co-partisan audiences in which the outgroup was defined only by the far left/right-mainstream split (left column).

There were small variations across the four political groups. In the co-partisan condition, participants on the right side of the political spectrum used slightly more covert tweets compared to participants on the left. In the cross-partisan condition, the patterns also varied between moderates and radicals. Mainstream right and left individuals had quite an increase in their covert signaling when the number of outgroup audience members changed from four to six. On the other hand, radical right and left participants exhibited a more linear increase in their proportion of shared covert tweets by outgroup size. Radical right and left participants were also more bi-modal, with one subgroup sharing almost only covert tweets when they were in the minority and another subgroup sharing a relatively lower proportion of covert tweets. The difference between moderates and more extreme participants was greater on the right compared to the left. Far right participants had fewer changes in their signaling strategy over varying outgroup sizes compared to moderate right participants. Though we could not determine an explanation for these differences with such small groups, our results point to some variation in the perceived ability to assort with similar others and the perceived cost of signaling.

\section{Discussion}

We have shown how individuals may be strategically altering their online communication based on their likely audiences, and that they do so in ways mostly consistent with the theory of covert signaling. This work connects to older theories of both identity signaling (Goffman, 1978; Berger, 2008) and audience design (Bell, 1984; Clark and Carlson, 1982; Clark and Schaefer, 1987; Fleming and Darley, 1991), but extends these theories by situating signaling behaviors in a sociocultural milieu and making clearer predictions based on context. The theory of covert signaling is inherently challenging to test empirically, because covert signals are, by definition, not easily perceived by outsiders who lack "insider" knowledge. Our methods were designed to overcome this difficulty by relying on differences in the responses among raters with different identity affiliations.

The theory predicts that individuals should use more covert signaling in more heterogeneous groups or when they are in the minority. We found support for this prediction in the ways people shared political speech in a behavioral experiment. We observed the highest levels of covert signaling when audiences consisted almost entirely of cross-partisans, supporting the notion that covert signaling is a strategy for avoiding detection by hostile outgroup members. Of note, we selected tweets for our study at a time of heightened partisan divisions: the four weeks preceding the 2020 U.S. presidential election. Consequently, these tweets mostly discussed the opposing political party. This focus was reflected in our behavioral experiment, where we did not observe an effect of audience composition when all members 
were (more or less extreme) co-partisans. In that societal context, participants might have perceived the cost of dislikes to be minimal and have likely focused on partisan disputes in their real-life conversations happening around that time. Future work testing the theory of covert signaling should also examine signaling strategies in co-partisan conversations during times of salient intra-group political divisions.

We found no significant effect of cost in our experiment. In previously published formal models (Smaldino et al., 2018; Smaldino and Turner, 2021), costs translated into observable differences in payoffs of agents, which affected their likelihood of becoming a target for imitation by others. It is likely that the differences in costs in our experimental conditionswhich involved a maximum difference in losses of only 20 cents between high- and low-cost conditions - were insufficient to motivate strong differences in behavior. The mathematical model of our experimental design, described above, helps to explain why the effect of audience composition (i.e., how much of the audience are outgroup members) should be so much stronger than the effect of cost. However, the effect of cost is even smaller than we expected. Future work should take into account stronger differences in potential losses to investigate differences in the cost of dislikes.

We found small differences in the use of covert tweets between far left/right participants and moderates. The theoretical models that inspired this study (Smaldino et al., 2018; Smaldino and Turner, 2021) make no explicit predictions about differences between political groups, though differences could be explained from the perceived ability to assort with similar others or in the perceived cost of being exposed to dissimilar others. In this case, some of the more politically extreme participants might consider the cost of being dissimilar to be high in the cross-partisan condition no matter the side of the outgroup, as they might consider other left- or right-leaning people as an outgroup as well. This might be even more true for far right participants who tend to consider Twitter as a left-leaning community. We hope to continue investigating more subtle differences in perceived outgroup members and related costs.

Our study reflects the complexity of how strategies of identity signaling can vary across communities and time. In the real world, including Twitter, communities are highly assortative and individuals can often restrict interaction partners to members of their ingroups (Bishop, 2009; Bakshy et al., 2015; Mosleh et al., 2021). Twitter networks therefore tend to be segregated, with conversations mostly occurring within coarse-grained political groups. This assortment drove our methods for the selection of tweets reflecting political identity. Future work should explore how changes in assortativity in and out of social media influences the use of covert signaling online.

Another direction for future empirical work on covert signaling in more natural settings is the analysis of the dynamic relationship between covert signaling and social networks. Specifically, individuals who are more likely to use overt signaling might end up in more homogeneous networks, either by choice or because they are shunned by disagreeing audiences. In our experimental design, the audience composition was fixed but in reality networks change after individuals express their opinions and identities over time. Signal type and utility can also be affected by changes in the network. For example, as familiarity with initially-covert signals grows beyond insider networks those signals can become overt (as with the recent case of the anti-Biden catchphrase "Let's go Brandon." (Long, 2021)). In our study, participants did not receive direct feedback after each round so did not have the chance to refine their 
signaling over time, but we hope to continue to refine our experiment to investigate further the co-evolutionary dynamics of signals and networks.

Our empirical study could not discern intent on the part of either signalers or receivers. Signalers did change their signaling strategy by using proportionally more covert tweets as the audience contained more outgroup members. We tried to construct a situation that would resemble identity signaling, where each participant could only share tweets from their own political side and were rewarded for being only correctly perceived by outgroup members. However, the participants may be trying to maximize payoffs irrespective of sharing their identity. To further test the theory of covert signaling we should study situations where we know individuals want to share their identity. Furthermore, we should differentiate outgroup receivers who are "churlish", disliking any signal that they do not see as ingroup (Smaldino and Turner, 2021) from those who actually understand the true intent of a covert tweet. We hope to continue disentangling the intents of both identity signalers and receivers and develop a theory that takes into account these nuances.

This work provides three specific pathways to develop and refine the theory of covert signalling. First, our findings shed light on the complexities of measuring the covertness of signals in a real-world setting. Our study design assumed a relatively clear dichotomy between overt and covert signaling, in line with prior modeling work (Smaldino et al., 2018; Smaldino and Turner, 2021). However, our results indicate that the covert-overt distinction is likely more continuous than dichotomous and that signal vocabularies may be heterogeneously distributed even among ingroup members. For example, even though outgroup members mostly disliked overt tweets, some disliked covert tweets as well. In that case, the utility of signaling with a given covertness level will depend on the cost-benefit tradeoffs regarding successful ingroup detection vs. the costs of outgroup detection. The continuous nature of covertness is an important topic for future theoretical and empirical work.

Second, our findings highlight other strategies that individuals might use when signaling in heterogeneous networks beyond switching from overt to covert signals. We find here that participants were overall more cautious with what they shared in heterogeneous environments, sharing fewer tweets overall. In case of a potential higher cost of being disliked by the outgroup, many might believe that the benefits of identity signaling to the ingroup might not be strong enough to compensate for the potential cost of being disliked by the outgroup, and thus decide to reduce the amount of signaling altogether. Future iterations of the theory of covert signaling could model not only the benefits of covert vs. overt signals but also consider the decision to signal in the first place.

Finally, in large, multicultural societies, identity is both critical and complicated. It is multidimensional and contextual (Roccas and Brewer, 2002; Smaldino, 2019b), and even political identity is more nuanced than the simple unidimensional left-right consideration implicit in this work. Indeed, our experiment did not afford participants the oblique choice to signal about something related to a different identity. The multidimensional nature of identity is discussed at length in a previous theory paper on covert signaling (Smaldino, 2019a) but not included in the models for tractability. Instead of using fewer tweets, our participants could have preferred to share different types of tweets. Future modeling and empirical testing of the theory of covert signaling should investigate how having multiple dimensions for identity signaling can influence the decision to use covert or overt signals.

Our analysis suggests that people adjust their political speech according to strategic in- 
centives, in ways predicted by our formal mathematical and computational models. Our work also points to specific areas where the theory of covert signaling could be improved. We believe this work provides support for calls to increase the integration of formal modeling with mainstream social science research (Bruch and Atwell, 2015; Muthukrishna and Henrich, 2019; Page, 2018; Smaldino, 2017, 2019a; van Rooij and Baggio, 2021). Formal models provide guidelines for assessing the scope of a theory - the constraints required for the theory to apply (Walker and Cohen, 1985). Our study was designed explicitly to test predictions from a formal model of covert signaling. To enable further theory development, additional models of overt and covert political signaling could be formally developed and their predictions compared with those of the current model.

Our work highlights that even deciding whether to classify communication as "political" is inherently context-dependent. The significance of a statement depends on the circumstances in which it is communicated and on the background knowledge of the receiver. This indicates that automated methods to detect political speech online (e.g., Grinberg et al., 2019) are likely restricted to detecting only overt speech. Such classifiers will likely miss most if not all covert signals, and will therefore ignore the strategic use of information that is simultaneously interpreted in different ways by different audience members. When speech is public, audiences are diverse, and identity matters, at least some identity-related speech is likely to be encrypted.

Overt political speech at its worst amounts to hate speech, in which cross-partisans are vilified and even dehumanized. At minimum, public political speech in the U.S. increasingly reflects affective polarization, in which individuals draw clear culture differences between "us" and "them" along partisan lines (Mason, 2018; Abramowitz and McCoy, 2019; Iyengar et al., 2019) and may share information for the purpose of declaring coalitional alignment rather than to communicate knowledge of the world (Marwick, 2018; Osmundsen et al., 2021). The consequences of this sort of continued polarization are probably stark. Our study suggests that overtly parochial speech will be more common when individuals can more easily assort into networks of like-minded individuals, particularly when those individuals are politically engaged with partisan media. There is evidence that, at least in the U.S., media is growing not only increasingly partisan, but is actively stoking the fires of partisanship (Klein, 2020; Taibbi, 2020).

For a diverse society to function effectively and cooperatively despite cultural differences, people must maintain some level of civility in public discourse, in which members of other groups are respected even if they are not always included. We should accordingly expect coded language and other covert identity signaling to be common, because diversity implies a variety of norms, goals, and experiences among individuals who will at least sometimes seek similar company. Covert signaling may be a sign of a functioning cosmopolitanism (Smaldino and Turner, 2021). However, it is also possible that covert signaling is indicative that some people have reasons to fear having their true identities publicly revealed. The benefit of covert signaling therefore may depend on the domains in which people interact and cooperate, and the topics that are allowed or proscribed in public discourse. Studies of covert signaling are increasingly important to understand the contextual implications of communication in a culturally diverse landscape. 


\section{Acknowledgments}

This work was supported by ARO grant W911NF-20-1-0220. For helpful comments on earlier drafts, we thank anonymous reviewers, Greg Bryant, Jonas Dalege, Tom Flamson, Riccardo Fusaroli, Mario Molina, Henrik Olsson, Richard McElreath, and discussants in the department of Human Behavior, Ecology and Culture at the Max Planck Institute for Evolutionary Anthropology.

\section{References}

Abramowitz, A. and McCoy, J. (2019). United States: Racial resentment, negative partisanship, and polarization in Trump's America. The ANNALS of the American Academy of Political and Social Science, 681(1):137-156.

Abramowitz, A. I. and Webster, S. (2016). The rise of negative partisanship and the nationalization of us elections in the 21st century. Electoral Studies, 41:12-22.

Bakshy, E., Messing, S., and Adamic, L. A. (2015). Exposure to ideologically diverse news and opinion on facebook. Science, 348(6239):1130-1132.

Barth, F. (1969). Introduction. In Barth, F., editor, Ethnic Groups and Boundaries, pages 9-38. Little, Brown, New York.

Bell, A. (1984). Language style as audience design. Language in Society, 13(2):145-204.

Berger, J. (2008). Identity signaling, social influence, and social contagion. In Prinstein, M. J. and Dodge, K. A., editors, Understanding peer influence in children and adolescents, pages 181-199. Guilford Press New York, NY.

Berger, J. and Ward, M. (2010). Subtle signals of inconspicuous consumption. Journal of Consumer Research, 37(4):555-569.

Bishop, B. (2009). The big sort: Why the clustering of like-minded America is tearing us apart. Houghton Mifflin Harcourt.

Boyer, P. (2018). Minds make societies: How cognition explains the world humans create. Yale University Press.

Brewer, M. B. (1991). The social self: On being the same and different at the same time. Personality and Social Psychology Bulletin, 17(5):475-482.

Bruch, E. and Atwell, J. (2015). Agent-based models in empirical social research. Sociological Methods 86 Research, 44(2):186-221.

Castro, L. and Toro, M. A. (2007). Mutual benefit cooperation and ethnic cultural diversity. Theoretical Population Biology, 71(3):392-399.

Clark, H. H. and Carlson, T. B. (1982). Hearers and speech acts. Language, 58:332-373. 
Clark, H. H. and Schaefer, E. F. (1987). Concealing one's meaning from overhearers. Journal of Memory and Language, 26(2):209-225.

Cohen, S. and Wills, T. A. (1985). Stress, social support, and the buffering hypothesis. Psychological Bulletin, 98(2):310.

Copeland, R. (2019). Fired by google, a republican engineer hits back: 'there's been a lot of bullying'. The Wall Street Journal.

DellaPosta, D., Shi, Y., and Macy, M. (2015). Why do liberals drink lattes? American Journal of Sociology, 120(5):1473-1511.

Donath, J. (2014). The social machine: Designs for living online. MIT Press.

Donath, J. S. (1999). Identity and deception in the virtual community. In Kollock, P. and Smith, M., editors, Communities in cyberspace, pages 29-59. Routledge.

Fischer, H. (2015). Gay Semiotics: A Photographic Study of Visual Coding Among Homosexual Men. Cherry and Martin.

Flamson, T. and Barrett, H. (2008). The encryption theory of humor: A knowledge-based mechanism of honest signaling. Journal of Evolutionary Psychology, 6(4):261-281.

Flamson, T. and Barrett, H. C. (2013). Encrypted humor and social networks in rural brazil. Evolution and Human Behavior, 34(4):305-313.

Flamson, T. J. and Bryant, G. A. (2013). Signals of humor: Encryption and laughter in social interaction. In Dynel, M., editor, Developments in Linguistic Humour Theory, volume 1, pages 49-73. John Benjamins Publishing, Amsterdam.

Fleming, J. H. and Darley, J. M. (1991). Mixed messages: The multiple audience problem and strategic communication. Social Cognition, 9(1):25-46.

Galesic, M. and Bosnjak, M. (2009). Effects of questionnaire length on participation and indicators of response quality in a web survey. Public opinion quarterly, 73(2):349-360.

Goffman, E. (1978). The presentation of self in everyday life. Harmondsworth London.

Grice, H. P. (1975). Logic and conversation. In Cole, P. and Morgan, J. L., editors, Syntax and semantics: Speech acts, pages 41-58. Brill.

Grinberg, N., Joseph, K., Friedland, L., Swire-Thompson, B., and Lazer, D. (2019). Fake news on Twitter during the 2016 us presidential election. Science, 363(6425):374-378.

Halberstam, Y. and Knight, B. (2016). Homophily, group size, and the diffusion of political information in social networks: Evidence from Twitter. Journal of Public Economics, 143:73-88.

Hammond, R. A. and Axelrod, R. (2006). The evolution of ethnocentrism. Journal of Conflict Resolution, 50(6):926-936. 
Henderson, R. and McCready, E. (2017). How dogwhistles work. In JSAI International Symposium on Artificial Intelligence, pages 231-240. Springer.

Hiaeshutter-Rice, D., Neuner, F. G., and Soroka, S. (2021). Cued by culture: Political imagery and partisan evaluations. Political Behavior, pages 1-19.

Huddy, L., Mason, L., and Aarøe, L. (2015). Expressive partisanship: Campaign involvement, political emotion, and partisan identity. American Political Science Review, pages $1-17$.

Iyengar, S., Lelkes, Y., Levendusky, M., Malhotra, N., and Westwood, S. J. (2019). The origins and consequences of affective polarization in the united states. Annual Review of Political Science, 22:129-146.

Iyengar, S., Sood, G., and Lelkes, Y. (2012). Affect, not ideology: A social identity perspective on polarization. Public Opinion Quarterly, 76(3):405-431.

Joireman, S. (2003). Nationalism and political identity. Bloomsbury.

Keegan, H. (2018). These political bumper stickers were at center of gun-brandishing road rage in Ozark. Springfield News-Leader.

Kirkpatrick, D. D. (2004). Speaking in the tongue of evangelicals. New York Times.

Klein, E. (2020). Why We're Polarized. Simon \& Schuster.

Kuran, T. (1989). Sparks and prairie fires: A theory of unanticipated political revolution. Public Choice, 61(1):41-74.

Kuran, T. (1995). The inevitability of future revolutionary surprises. American Journal of Sociology, 100(6):1528-1551.

Long, C. (2021). How 'Let's Go Brandon' became code for insulting Joe Biden. AP News.

López, I. H. (2015). Dog whistle politics: How coded racial appeals have reinvented racism and wrecked the middle class. Oxford University Press.

Loury, G. C. (1994). Self-censorship in public discourse: A theory of "political correctness" and related phenomena. Rationality and Society, 6(4):428-461.

Marwick, A. E. (2018). Why do people share fake news? a sociotechnical model of media effects. Georgetown Law Technology Review, 2(2):474-512.

Marwick, A. E. and boyd, d. (2014). Networked privacy: How teenagers negotiate context in social media. New Media \&5 Society, 16(7):1051-1067.

Mason, L. (2018). Uncivil agreement: How politics became our identity. University of Chicago Press.

McElreath, R., Boyd, R., and Richerson, P. J. (2003). Shared norms and the evolution of ethnic markers. Current Anthropology, 44(1):122-130. 
Merolla, D. M., Serpe, R. T., Stryker, S., and Schultz, P. W. (2012). Structural precursors to identity processes: The role of proximate social structures. Social Psychology Quarterly, $75(2): 149-172$.

Mesoudi, A. (2011). Cultural evolution: How Darwinian theory can explain human culture and synthesize the social sciences. University of Chicago Press.

Mosleh, M., Martel, C., Eckles, D., and Rand, D. G. (2021). Shared partisanship dramatically increases social tie formation in a twitter field experiment. Proceedings of the National Academy of Sciences, 118(7).

Moya, C. and Boyd, R. (2015). Different selection pressures give rise to distinct ethnic phenomena. Human Nature, 26(1):1-27.

Muthukrishna, M. and Henrich, J. (2019). A problem in theory. Nature Human Behaviour, $3(3): 221-229$

Nagle, A. (2017). Kill all normies: Online culture wars from 4chan and Tumblr to Trump and the alt-right. John Hunt Publishing.

Nettle, D. and Dunbar, R. (1997). Social markers and the evolution of reciprocal exchange. Current Anthropology, 38:93-99.

Osmundsen, M., Bor, A., Vahlstrup, P. B., Bechmann, A., and Petersen, M. B. (2021). Partisan polarization is the primary psychological motivation behind "fake news" sharing on Twitter. American Political Science Review.

Page, S. E. (2018). The model thinker: What you need to know to make data work for you. Hachette.

Pew Research Center (2021). Social media fact sheet. https://www. pewresearch.org/ internet/fact-sheet/social-media/.

Plant, R. (2004). Online communities. Technology in Society, 26(1):51-65.

Roccas, S. and Brewer, M. B. (2002). Social identity complexity. Personality and Social Psychology Review, 6(2):88-106.

Ronson, J. (2015). How one stupid tweet blew up Justine Sacco's life. The New York Times Magazine, page 20-20.

Searle, J. R. (1975). Indirect speech acts. In Cole, P. and Morgan, J. L., editors, Speech acts, pages 59-82. Brill.

Serpe, R. T. and Stryker, S. (1987). The construction of self and reconstruction of social relationships. Advances in Group Processes, 4(4):1-66.

Settle, J. E. (2018). Frenemies: How social media polarizes America. Cambridge University Press. 
Shelp, S. G. (2003). Gaydar. Journal of Homosexuality, 44(1):1-14.

Smaldino, P. (2019a). Better methods can't make up for mediocre theory. Nature, 575:9.

Smaldino, P. E. (2017). Models are stupid, and we need more of them. In Vallacher, R. R., Read, S. J., and Nowak, A., editors, Computational Social Psychology, pages 311-331. Routledge, New York.

Smaldino, P. E. (2019b). Social identity and cooperation in cultural evolution. Behavioural Processes, 161:108-116.

Smaldino, P. E., Flamson, T. J., and McElreath, R. (2018). The evolution of covert signaling. Scientific Reports, 8(1):1-10.

Smaldino, P. E. and Turner, M. A. (2021). Covert signaling is an adaptive communication strategy in diverse populations. Psychological Review, in press.

Sperber, D. and Wilson, D. (1986). Relevance: Communication and cognition. Harvard University Press Cambridge, MA.

Taibbi, M. (2020). Hate Inc.: Why Today's Media Makes Us Despise One Another. OR Books.

Van Duyn, E. (2018). Hidden democracy: Political dissent in rural America. Journal of Communication, 68(5):965-987.

van Rooij, I. and Baggio, G. (2021). Theory before the test: How to build high-verisimilitude explanatory theories in psychological science. Perspectives on Psychological Science, $16: 682-697$.

Walker, H. A. and Cohen, B. P. (1985). Scope statements: Imperatives for evaluating theory. American Sociological Review, 50:288-301.

Waring, T. M., Goff, S. H., and Smaldino, P. E. (2017). The coevolution of economic institutions and sustainable consumption via cultural group selection. Ecological Economics, 131:524-532.

Wimmer, A. (2013). Ethnic boundary making: Institutions, power, networks. Oxford University Press.

Yang, V. C., van der Does, T., and Olsson, H. (2021). Falling through the cracks: Modeling the formation of social category boundaries. Plos One, 16(3):e0247562. 


\section{SI Appendix for "Strategic Identity Signaling in Heterogeneous Networks"}

\section{Twitter data collection}

Table S1: News sites used to determine Twitter account engagement with far left/right politics. Initial 8 news accounts (from whom followers were drawn to provide the initial 80,000 seed accounts) are in bold.

\begin{tabular}{|c|c|c|}
\hline Left Sites & Twitter Handle & \# Followers \\
\hline Salon & @Salon & 975,000 \\
\hline Human Rights Campaign & $@ \mathrm{HRC}$ & 823,100 \\
\hline Think Progress & @thinkprogress & 808,500 \\
\hline Democracy Now & @democracynow & 742,000 \\
\hline Splinter & @splinter_news & 544,800 \\
\hline Young Turks & @TheYoungTurks & 414,000 \\
\hline Jezebel & @Jezebel & 318,600 \\
\hline Jacobin & @jacobinmag & 298,100 \\
\hline Daily Kos & @dailykos & 289,300 \\
\hline Feministing & @feministing & 230,200 \\
\hline Raw Story & @RawStory & 216,600 \\
\hline Right Wing Watch & @RightWingWatch & 178,800 \\
\hline TruthOut & @truthout & 178,200 \\
\hline New Republic & @newrepublic & 172,100 \\
\hline Chapo Trap House & @CHAPOTRAPHOUSE & 146,000 \\
\hline Alternet & @AlterNet & 139,100 \\
\hline Electronic Intifada & @intifada & 115,300 \\
\hline Truth Dig & @Truthdig & 96,000 \\
\hline Code Pink & @ codepink & 95,400 \\
\hline Crooks and Liars & @crooksandliars & 93,400 \\
\hline It's Going Down & @IGD_News & 87,700 \\
\hline Towleroad & @tlrd & 77,300 \\
\hline Common Dreams & @ commondreams & 76,300 \\
\hline Dissent Magazine & @DissentMag & 70,100 \\
\hline CounterPunch & @NatCounterPunch & 69,200 \\
\hline Free Press & @freepress & 58,900 \\
\hline
\end{tabular}




\begin{tabular}{llc}
\hline \hline Left Sites & Twitter Handle & \# Followers \\
\hline Libcom.org & @libcomorg & 52,400 \\
Care2 & @Care2 & 51,900 \\
In These Times & @inthesetimesmag & 43,000 \\
American Bridge 21st Century & @American_Bridge & 38,100 \\
Cop Block & @CopBlock & 26,200 \\
Institute for Policy Studies & @IPS_DC & 18,500 \\
In Defence of Marxism & @marxistcom & 16,200 \\
Earth First Journal & @efjournal & 15,600 \\
Democracy Chronicles & @demchron & 14,100 \\
North99 & @wearenorth99 & 14,000 \\
Workers World & @workersworld & 13,100 \\
Act.TV & @actdottv & 12,800 \\
Peacock Panache & @PeacockPanache & 12,200 \\
Occupy.com & @occupy & 11,200 \\
Egberto Willies & @EgbertoWillies & 10,500 \\
Center for a Stateless Society & @c4ssdotorg & 10,100 \\
Democratic Underground & @demunderground & 10,000 \\
\hline
\end{tabular}

\begin{tabular}{llc}
\hline \hline Right Sites & Twitter Handle & \# Followers \\
\hline Breitbart & @BreitbartNews & $1,300,000$ \\
The Blaze & @theblaze & 725,000 \\
Daily Caller & @DailyCaller & 719,600 \\
Heritage Foundation & @Heritage & 670,200 \\
Daily Wire & @realDailyWire & 416,000 \\
National Review & @NRO & 347,000 \\
FreedomWorks & @FreedomWorks & 291,100 \\
The Federalist & @FRLST & 262,000 \\
Life News & @LifeNewsHQ & 245,400 \\
Red State & @RedState & 229,000 \\
Conservative Review & @CR & 199,300 \\
The Rebel News & @RebelNewsOnline & 186,100 \\
Christian Post & @ChristianPost & 172,000 \\
Newsmax & @newsmax & 155,700 \\
Washington Free Beacon & @FreeBeacon & 120,400 \\
Independent Journal Review & @TheIJR & 115,100 \\
Chicks on the Right & @chicksonright & 98,900 \\
Daily Signal & @DailySignal & 71,400 \\
Far Left Watch & @FarLeftWatch & 60,900 \\
Federalist Society & @FedSoc & 60,100 \\
Human Events & @HumanEvents & 51,600 \\
Law Enforcement Today & @LawEnforceToday & 48,100 \\
BizPac Review & @BIZPACReview & 46,700 \\
\hline
\end{tabular}




\begin{tabular}{|c|c|c|}
\hline$\overline{\text { Right Sites }}$ & Twitter Handle & \# Followers \\
\hline American Spectator & @amspectator & 46,100 \\
\hline Christian Coalition of America & @ccoalition & 42,400 \\
\hline The Right Scoop & @trscoop & 41,000 \\
\hline Numbers USA & @NumbersUSA & 36,800 \\
\hline Lifezette & @LifeZette & 34,300 \\
\hline Energy Citizens & @energycitizens & 33,700 \\
\hline Accuracy in Media & @AccuracyInMedia & 30,100 \\
\hline Politichicks & @ThePolitiChicks & 25,100 \\
\hline Tenth Amendment Center & @TenthAmendment & 23,000 \\
\hline The Resurgent & @resurgent & 21,800 \\
\hline Richochet & @Ricochet & 21,100 \\
\hline American Greatness & @theamgreatness & 20,700 \\
\hline Ami Magazine & @Ami_Magazine & 20,500 \\
\hline Bearing Arms & @BearingArmsCom & 19,100 \\
\hline Weasel Zippers & @weaselzippers & 18,500 \\
\hline Claremont Institute & @ClaremontInst & 17,700 \\
\hline Crisis Magazine & @CrisisMag & 16,600 \\
\hline The College Fix & @CollegeFix & 16,300 \\
\hline PanAm Post & @PanAmPost & 15,500 \\
\hline Disrn & @DisrnNews & 14,800 \\
\hline Liberty Nation & @libertynation & 13,700 \\
\hline Media Equalizer & @MediaEqualizer & 12,800 \\
\hline Communities Digital News & @CommDigiNews & 12,400 \\
\hline The American Mind & @theammind & 12,000 \\
\hline Intellectual Takeout & @intellectualTO & 11,600 \\
\hline Media Trackers & @mediatrackers & 11,100 \\
\hline Citizen Free Press & $@$ CitizenFreePres & 10,200 \\
\hline
\end{tabular}



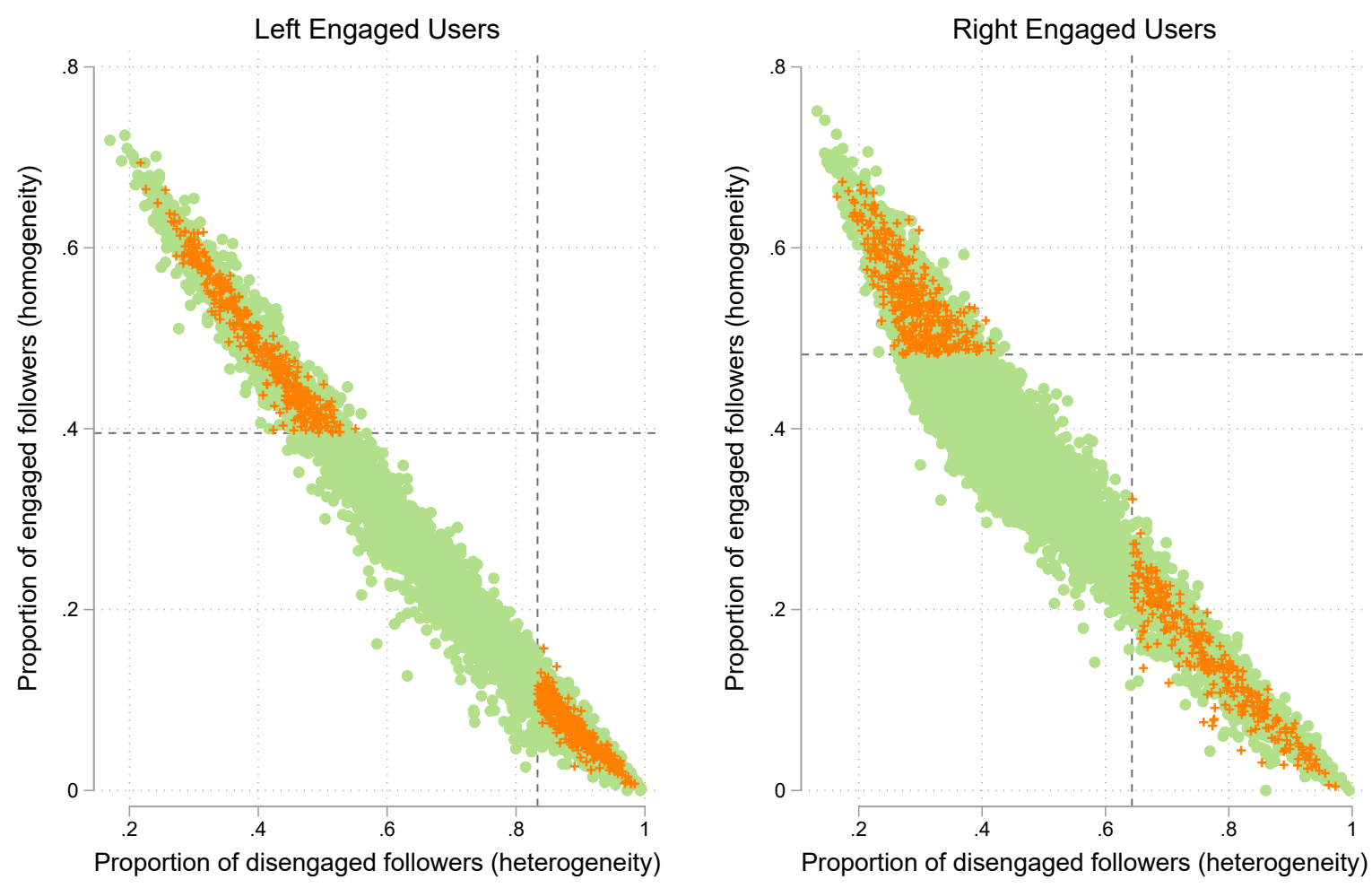

Figure S1: Relationship between heterogeneity and homogeneity scores among the initially considered 16,398 Twitter users (green dots; $r=.99$ ). Orange crosses denote 1,366 Twitter users that were selected for the rating study because they were in the top $20 \%$ by either homogeneity or heterogeneity scores and had tweets that matched our selection criterion. 


\section{Participant selection questionnaire and criteria}

We used CloudResearch, a panel service associated with Mechanical Turk (MTurk), to select 3,027 individuals who were identified in CloudResearch screening survey as having a "moderate", "very liberal", or "very conservative" political orientation. They were invited to a brief survey in which they were asked to solve a political literacy quiz and report on their news-following habits, the political groups they identify with, their familiarity with different political groups and movements, and their opinions about different political issues.

Based on the survey responses, we selected four groups of raters as described in Figure S2. To select far left and far right raters, we focused on their news sources and identities. We included individuals who reported keeping up with the news using at least one far left or far right source regularly (see TableS3 in the SI Appendix) or who identified with a far left or far right identity (see Table S4 in the SI Appendix). In addition, we screened out participants who identified with inconsistent political views (e.g., followed a far right news source but self-described as very liberal) or with inconsistent political identities (e.g., identified with a far left identity and as Republican). Although it may be perfectly reasonable to follow cross-partisan news accounts, we excluded these individuals to reduce a potential source of noise in our data.

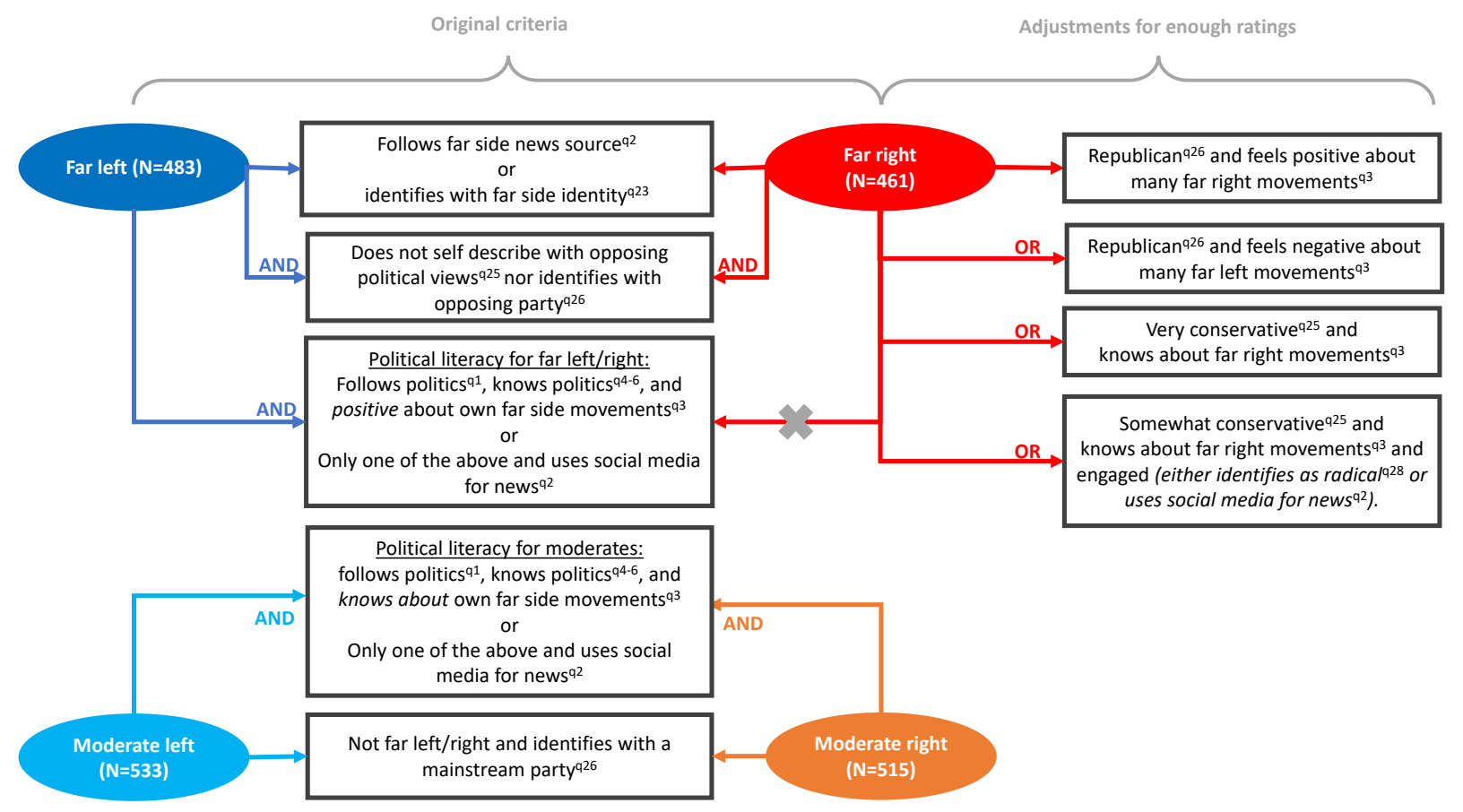

Figure S2: The process of selection of raters. Superscripts refer to the survey question (see Questionnaire below) used for each criterion.

In order to select raters with at least a minimum of political literacy, we selected participants who reported following the news at least once a week, answered two out of three questions correctly in the political literacy quiz, and were in the top $50 \%$ by their positivity toward their own far side political movements (see Table S5 in the SI Appendix). Because our analysis focused on rating or sharing tweets, we wanted to oversample people familiar 
with social media and therefore we also added to the pool participants who had only one of the criteria of political literacy but listed a social media site as their regular source of news (Twitter, Facebook, Reddit, 4chan, 8kun, ctree, and forums). To select moderate left and right raters, we included all participants who identified as Democrat or Republican and were not marked as having a far side ideology. In addition, we used the same political literacy criteria as for far side participants, except we selected those who were in the top $75 \%$ in knowledge far side movements (regardless of feeling positive about them).

Given these criteria, our pool of potential raters included fewer far right participants compared to all other groups. This is not surprising given that people who participate in Amazon's Mechanical Turk platform tend to lean Democrat (Levay et al., 2016). We therefore broadened our criteria for far right raters, while still retaining the focus on far right ideology, identity, and a minimum of political literacy. We included participants who identified as Republican and, compared to all right-leaning participants, were in the top 10\% for feeling positive about many far right movements or top $10 \%$ for feeling negative about far left movements. We also added participants who self-described as very conservative and were in the top $75 \%$ of right-leaning individuals according to their knowledge of far right movements. Finally, we added to the pool participants who identified as somewhat conservative, were in the top $75 \%$ according to their knowledge of far right movements, and were engaged (either self-identified as radical or used social media for news). We used this pre-selected pool for both the rating and classification of tweets and for the behavioral experiment. 


\section{Questionnaire}

1 Political literacy

[q1] Would you say you follow what's going on in government and public affairs...

More than once a day

Every day

More than once a week

Once a week

At least once a month

Less than once a month

Never

2 Political sources

[q2] Which of the following sources do you regularly seek out to keep up with politics and election news?

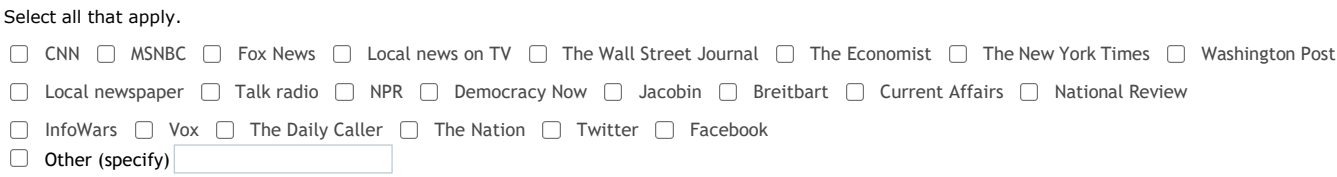

3 Feelings political movements

[q3] Select how you feel about each of the following groups or movements:

\begin{tabular}{|c|c|c|c|c|}
\hline American Party of Labor & 0 & 0 & 0 & 0 \\
\hline Anonymous & O & 0 & 0 & 0 \\
\hline Black Lives Matters & 0 & 0 & 0 & 0 \\
\hline Democratic Socialists of America & 0 & 0 & 0 & 0 \\
\hline Fraternal Order of Alt-Knights & 0 & 0 & 0 & 0 \\
\hline \multirow[t]{2}{*}{ League of the South } & 0 & 0 & 0 & 0 \\
\hline & Positive & Neutral & Negative & Never heard of it \\
\hline Occupy Wall Street & 0 & 0 & 0 & 0 \\
\hline Unite the Right & 0 & 0 & 0 & 0 \\
\hline Vanguard America & 0 & 0 & 0 & 0 \\
\hline QAnon & 0 & 0 & 0 & 0 \\
\hline Loyal White Knights & 0 & 0 & 0 & 0 \\
\hline Antifa & 0 & 0 & 0 & 0 \\
\hline Workers World Party & 0 & 0 & 0 & 0 \\
\hline American Identitarian & 0 & 0 & 0 & 0 \\
\hline Indivisible & O & 0 & 0 & 0 \\
\hline Communist Party USA & 0 & 0 & 0 & $\bigcirc$ \\
\hline Identity Evropa & 0 & 0 & 0 & 0 \\
\hline Stormer Book Club & 0 & 0 & 0 & 0 \\
\hline Traditionalist Worker Party & 0 & 0 & 0 & 0 \\
\hline
\end{tabular}


4 Political questionnaire

In the next three questions, we are looking for your intuitive answers. Please do not look up the correct answers online - your answers will have absolutely no

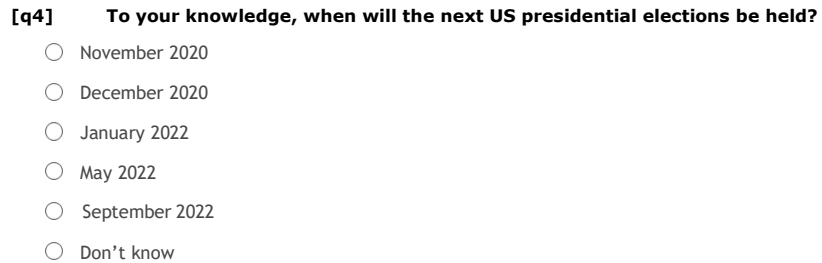

[q5] To your knowledge, which party has control of the US House of Representatives?

Democratic party

Republican party

Other

Don't know

[q6] To your knowledge, which party has control of the US Senate?

Democratic party

Republican party

Other

Don't know

5 General opinions

The following pairs of statements will help us understand how you feel about a number of issues. For each pair, please tell us which statement comes closer to you

[q7] Which of the following statements comes closest to your view?

The government should do more to help needy Americans, even if it means going deeper into debt

The government today can't afford to do much more to help the needy

[q8] Which of the following statements comes closest to your view?

Racial discrimination is the main reason why many black people can't get ahead these days

Black people who can't get ahead in this country are mostly responsible for their own condition

[q9] Which of the following statements comes closest to your view?

The best way to ensure peace is through military strength

Good diplomacy is the best way to ensure peace

[q10] Which of the following statements comes closest to your view?

Government is almost always wasteful and inefficient

vs.

Government often does a better job than people give it credit for

[q11] Which of the following statements comes closest to your view?

Government regulation of business is necessary to protect the public interest

Government regulation of business usually does more harm than good

[q12] Which of the following statements comes closest to your view?

Poor people today have it easy because they can get government benefits without doing anything in return

Poor people have hard lives because government benefits don't go far enough to help them live decently

[q13] Which of the following statements comes closest to your view?

Immigrants today strengthen our country because of their hard work and talents

vs.

Immigrants today are a burden on our country because they take our jobs, housing and health care 


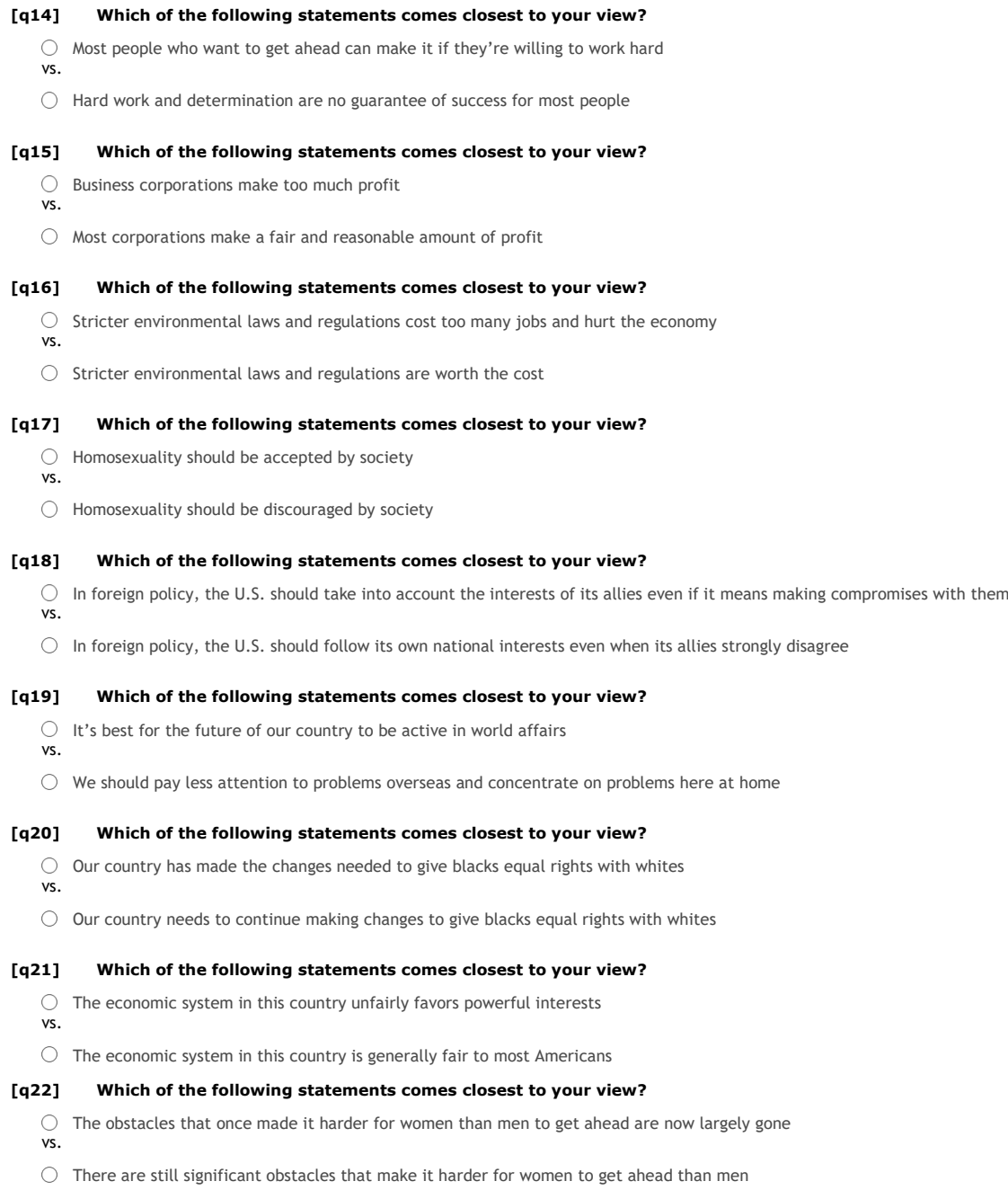


6 Specific identities

The following list contains various words that people might use to describe their views.

[q23] Which of these words would you say apply to you?

Feel free to choose as many words as you like.

$\square$ Alt-right $\square$ America First $\square$ Anarchist $\square$ Anti-racist $\square$ Anti-vaccine $\square$ Communist $\square$ Democrat $\square$ Environmentalist $\square$ Feminist

$\square$ Independent $\square$ Judeo-Christian Values $\square$ Libertarian $\square$ Moderate $\square$ Nationalist $\square$ Patriot $\square$ Pro-life $\square$ Progressive $\square$ Republican

$\square$ Socialist $\square$ Tea Party

$\square$ Other (specify)

7 Specific anti

[q24] Next, which of these would you say you are opposed to?

Feel free to choose as many words as you like.

$\square$ Alt-right $\square$ America First $\square$ Anarchist $\square$ Anti-racist $\square$ Anti-vaccine $\square$ Communist $\square$ Democrat $\square$ Environmentalist $\square$ Feminist

$\square$ Independent $\square$ Judeo-Christian Values $\square$ Libertarian $\square$ Moderate $\square$ Nationalist $\square$ Patriot $\square$ Pro-life $\square$ Progressive $\square$ Republican

$\square$ Socialist $\square$ Tea Party

$\square$ Other (specify)

8 General identity questions

[q25] In general, would you describe your political views as...

Very liberal

Liberal

Moderate

Conservative

Very conservative

[q26] In politics today, do you consider yourself a...

Democrat

Republican

Independent

Other (specify)

$9 \quad$ Strength id

[q27] How strongly do you consider being a [political party] to be part of your core identity, of who you are?

Not at all

A little bit

A moderate amount

A large amount

[q28] Relative to mainstream political views in the US, to what extent do you consider yourself radical?

Not at all radical

Somewhat radical

Radical

Very radical 
10 Own probability

[q29] What is the percent chance that you will vote in the upcoming 2020 U.S. Presidential election?

Please enter a number from 0 to 100 , where 0 means that you will definitely not vote, and 100 that you will definitely vote. If you have already voted, please ente $\%$

12.1 Own voting intentions

[q30] If you do vote in the election, what is the percent chance you will vote for each of the candidates below?

For each candidate, please enter a number from 0 to 100 , where 0 means that you will definitely not vote for that candidate, and 100 that you will definitely vote Joe Biden (Democrat)

Donald Trump (Republican)

Someone else

13 Social probability

Now we would like you to think of your friends, family, colleagues, and other acquaintances who live in your state, are at least 18 years of age, and who you have communicated with at least briefly within the last month, either face-to-face, or otherwise. We will call these people your social contacts.

[q31] What percentage of your social contacts that live in your state are likely to vote in the upcoming 2020 U.S. Presidential election? Please enter a number from 0 to 100 , where 0 means that you think none of your social contacts will vote, and 100 means that all of your social contacts will vote $\%$

14.1 Social circle voting intentions

[q32] Out of all your social contacts who live in your state and are likely to vote in the 2020 U.S. Presidential election, what percentage do you think will vote for each of the candidates below?

For each candidate, please enter a number from 0 to 100 , where 0 means that none of your social contacts will vote for that candidate, and 100 means that all of Joe Biden (Democrat)

Donald Trump (Republican)

Someone else

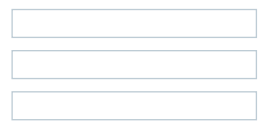

15 Demo

Before we end, we have a few questions about yourself.

[q33] What is your age?

years

[q34] What is your gender?

Male

Female

Other

[q35] What is your highest level of formal education?

Did not finish high school

High school diploma

Some college

Bachelor's degree

Graduate degree

[q36] What is your race and/or ethnicity?

Please check all that apply

$\square$ White

$\square$ Black or African American

$\square$ Hispanic, Latino, or Spanish origin

$\square$ American Indian or Alaska Native

$\square$ Asian

$\square$ Native Hawaiian or Other Pacific Islander

$\square$ Some other race or ethnicity: 
Table S3: Far left and far right favorite news source

\begin{tabular}{ll}
\hline Far left & Far right \\
\hline \hline Jacobin & Breitbart \\
Vox & Infowars \\
The Young Turks & Twitchy \\
Chapo & RedState \\
DailyKos & Gateway Pyndit \\
Current Affairs & Daily Caller \\
& 4chan \\
& The Blaze \\
& 8kun \\
& Daily Wire \\
& Daily Mail \\
& Citizen Free Press \\
& Conservative Treehouse \\
\hline
\end{tabular}

Table S4: Farl left and far right identities

\begin{tabular}{ll}
\hline Far left & Far right \\
\hline \hline Anarchist & Alt-Right \\
Communist & Tea Party \\
Socialist & Confederate \\
& Identitarian \\
& Proud Boys \\
\hline
\end{tabular}


Table S5: Far left and far right mouvements

\begin{tabular}{ll}
\hline Far left & Far right \\
\hline \hline BLM & Unite the Right \\
Antifa & Stormer Book Club \\
Anonymous & League of the South \\
Indivisible & Traditionalist Worker Party \\
Occupy & Vanguard America \\
Communist Party USA & Loyal White Knights \\
Democratic Socialists of America & Fraternal Order of Alt-Knights \\
Workers World Party & American Identitarian \\
American Party of Labor & Identity Exropa \\
\hline
\end{tabular}

\section{Rating of tweets}

Online participants answered four questions for a total of 5,215 tweets (Figure S3). Of those, 4,752 received enough ratings to be evaluated according to various criteria (Table S6). A total of 154 tweets were pre-selected as covert and overt tweets based on these criteria.

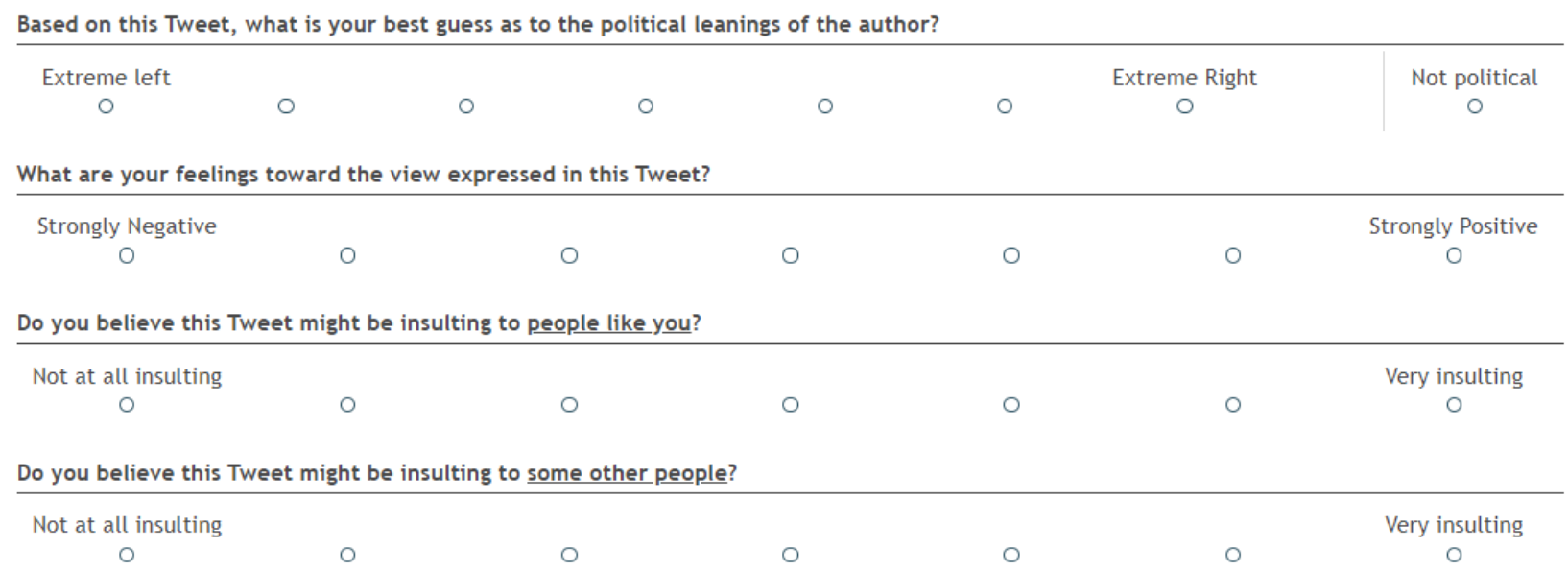

Figure S3: Online questionnaire for rating tweets

Figure S4 shows the mean tweet-level scores for each of the items within our two dimensions used to automatically pre-select tweets, separately for four different groups of raters defined in relationship to the political orientation of the tweet: co-partisan radicals, co-partisan moderates, cross-partisan radicals and cross-partisan moderates (for a total of $\mathrm{N}=1,992$ raters). For example, in the case of a right leaning tweet, co-partisans would be right-leaning raters and cross-partisan left-leaning. Of all tweets, 92 were marked as overtly political and 62 as covertly political. As described above, each tweet was given a score based on the average ratings for each of the four groups, Figure S4 presents the mean of the scores across all tweets.

According to the definition of covert signaling, all raters should receive the political signal 
Table S6: Criteria used to select covert and overt tweets for the behavioral experiment, based on ratings given by different political groups

\begin{tabular}{|c|c|}
\hline Criteria for left (right) covert tweets & \\
\hline $\begin{array}{l}\text { Co-partisan difference in tweets' perceived po- } \\
\text { litical orientation }\end{array}$ & $\begin{array}{l}\text { Difference between average political orienta- } \\
\text { tion ratings }{ }^{*} \text { given by far and moderate left } \\
\text { (right) raters is above } 80 \text { th percentile. }\end{array}$ \\
\hline Co-partisan difference in affective response & $\begin{array}{l}\text { Difference between average negative affect* } \\
\text { experienced by moderate and far left (right) } \\
\text { raters is above } 80 \text { th percentile. }\end{array}$ \\
\hline $\begin{array}{l}\text { Neutrality of moderates-rated political orien- } \\
\text { tation }\end{array}$ & $\begin{array}{l}\text { Average rating of political orientation given by } \\
\text { left (right) moderates is neutral or mildly left } \\
\text { (right). }\end{array}$ \\
\hline Moderates' affective response & $\begin{array}{l}\text { Average negative affect experienced by left } \\
\text { (right) moderates is low ( }<=4 \text { on a } 7 \text {-point } \\
\text { scale). }\end{array}$ \\
\hline Political content & $\begin{array}{l}\text { At least } 75 \% \text { of far left (right) raters think the } \\
\text { tweet is political. }\end{array}$ \\
\hline \multicolumn{2}{|l|}{ Criteria for left (right) overt tweets } \\
\hline $\begin{array}{l}\text { Cross-partisan difference in political orienta- } \\
\text { tion }\end{array}$ & $\begin{array}{l}\text { Difference between average political orienta- } \\
\text { tion ratings* given by left and right raters is } \\
\text { below } 20 \text { th percentile. }\end{array}$ \\
\hline Cross-partisan difference in affective response. & $\begin{array}{l}\text { Difference between average negative affect* } \\
\text { experienced by left and right raters is above } \\
\text { 80th percentile. }\end{array}$ \\
\hline Co-partisan similarity in affective response & $\begin{array}{l}\text { Difference between average negative affect* } \\
\text { experienced by far and moderate left (right) } \\
\text { raters is below } 20 \text { th percentile. }\end{array}$ \\
\hline Political content & $\begin{array}{l}\text { At least } 75 \% \text { of all raters think the tweet is } \\
\text { political. }\end{array}$ \\
\hline
\end{tabular}

*To make differences comparable across tweets, differences were divided by the sum of standard deviations of ratings given by each group of raters. 
Percent believe not political (0-1)
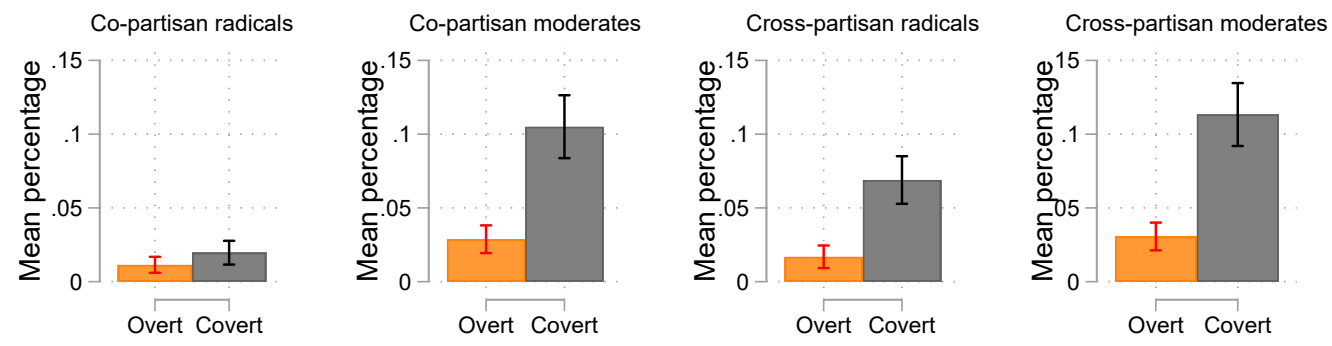

Political identity radicalness (0 to 3 )
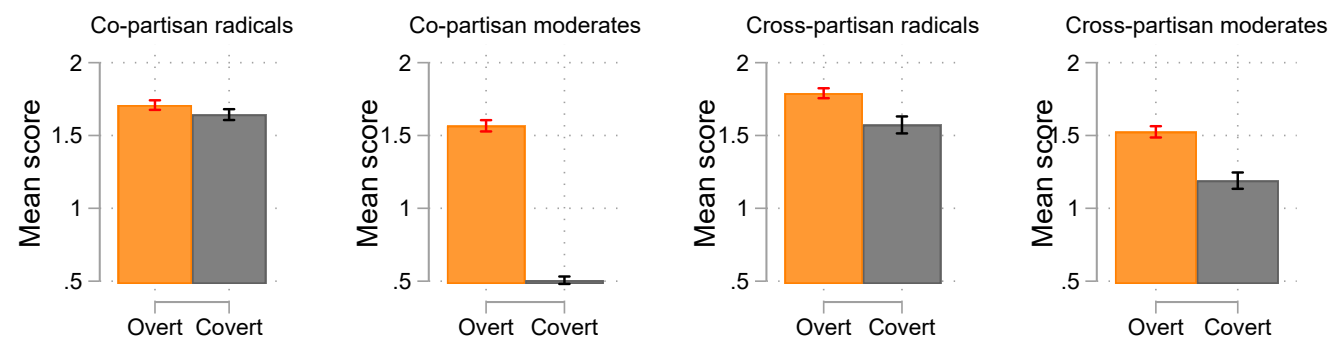

Negative feelings towards views (-3 to 3 )
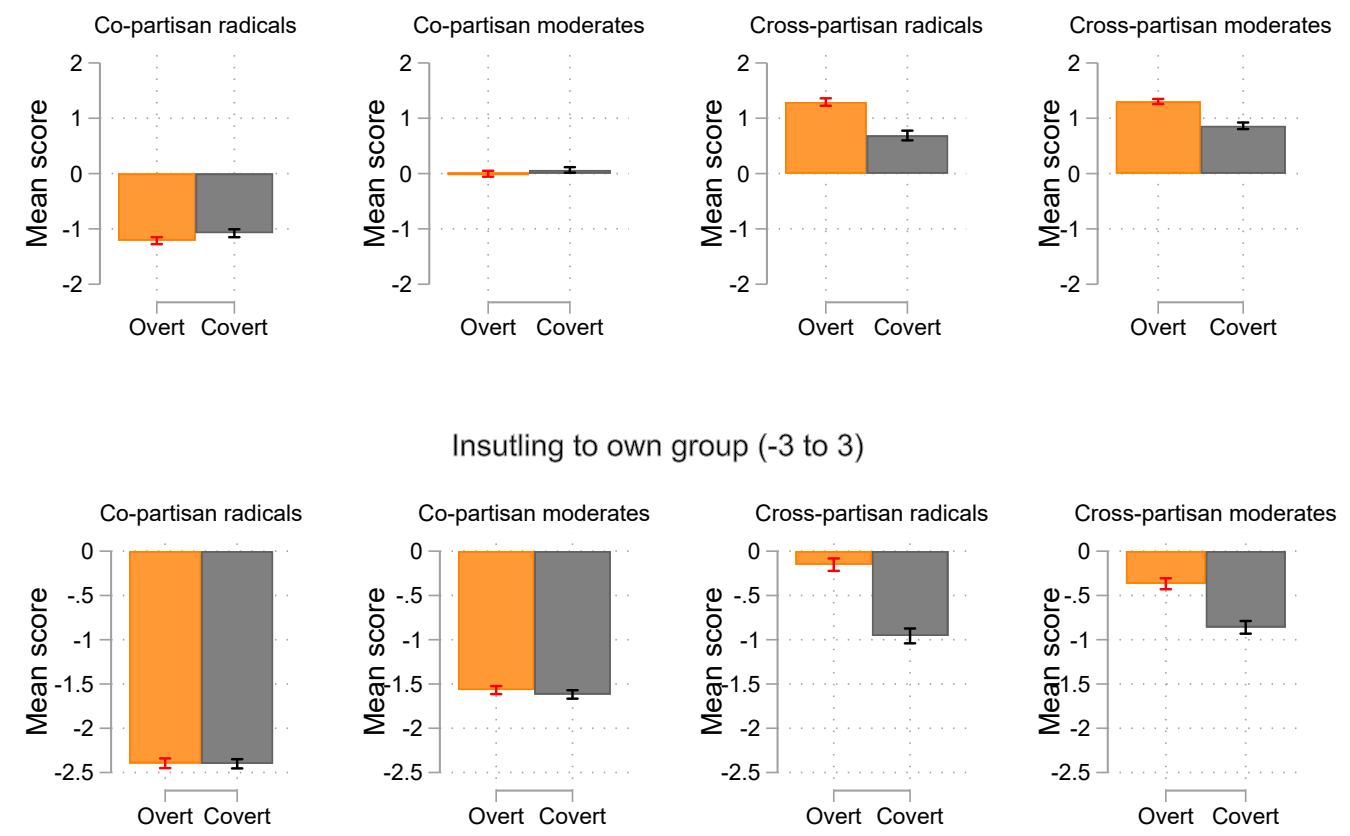

Figure S4: Mean tweet-level scores on four items from co-partisan, cross-partisan, moderate, and radical raters, $\mathrm{N}=154$. Error bars represent standard errors around the mean. 
of overt tweets but only ingroup (co-partisan) radicals should receive the political signal of covert tweets. This is reflected in the first two rows of Figure S4. On the one hand, overt tweets are rarely viewed as not political across all four groups (orange bar in the first row Figure S4). On the other hand, covert tweets are rarely selected as non political by copartisan radicals but quite more often by the three other groups (grey bar in the first row Figure S4). Regarding guessing the political identity of the tweet author, overt tweets were considered as radical for all groups, but covert tweets were not considered as radical by co-partisan moderates compared to co-partisan radicals (grey bar in the second row, first two columns in Figure S4). Cross-partisan raters considered covert tweets still as pretty radical. We believe this is due to the opposite political side being more sensitive to any signal from the other political group, even if they do not quite understand it (and tend to mark it as non political). Both cross-partisan groups, however, still marked it as less radical than co-partisan radicals.

As expected, cross-partisan raters disliked all tweets from the opposite side of the political spectrum, but disliked overt tweets more than covert tweets. Co-partisan raters did not view selected overt and covert tweets negatively (third row, first two columns in Figure S4), nor did they view them as insulting to people like them (fourth row first two columns in Figure S4. As expected, co-partisan radical raters were more positive and viewed the tweets as less insulting compared to co-partisan moderate raters. However, for co-partisan groups, there was no difference in the perception of overt or covert tweets. The difference in affective response between covert and overt tweets only appears within the ratings of cross-partisan members (last two columns of the last two rows of Figure S4). Members of the opposite political side viewed selected overt tweets more negatively and more insulting to their group compared to covert tweets. These differences in average ratings across measures give some evidence that the pre-selected tweets represented overt and covert political signaling at the time of the 2020 presidential elections. We further test this by comparing their usage on Twitter in the next Supplementary section. 


\section{Description of covert and overt tweets' networks}

One of the predictions of the general theory of covert signaling is that covert signaling should be more prevalent among individuals in more heterogeneous communities. To explore if this was true for our pre-selected tweets in a real world context, we compared the Twitter networks (heterogeneous vs. homogeneous) of the Twitter accounts for the full sample of tweets preselected as covert and overt $(\mathrm{N}=154)$. As shown in Figure $\mathrm{S} 5$, both overt and covert political tweets were more likely to be from Twitter accounts with homogeneous followers compared to heterogeneous followers ( $61 \%$ of overt tweets were in heterogeneous contexts and $55 \%$ of covert tweets). Covert tweets were more likely than overt tweets to appear in a heterogeneous context: $45 \%$ of covert tweets were used in heterogeneous contexts compared to $39 \%$ of overt tweets. In other words, all political speech is more likely to happen in homogeneous Twitter networks compared to heterogeneous networks, but when political speech happens in heterogeneous networks it is more likely to be covert. These results are in line with the theory of covert signaling and point to the reasonability of our measures.

Twitter account network

$\square$ Homogeneous $\square$ Heterogeneous

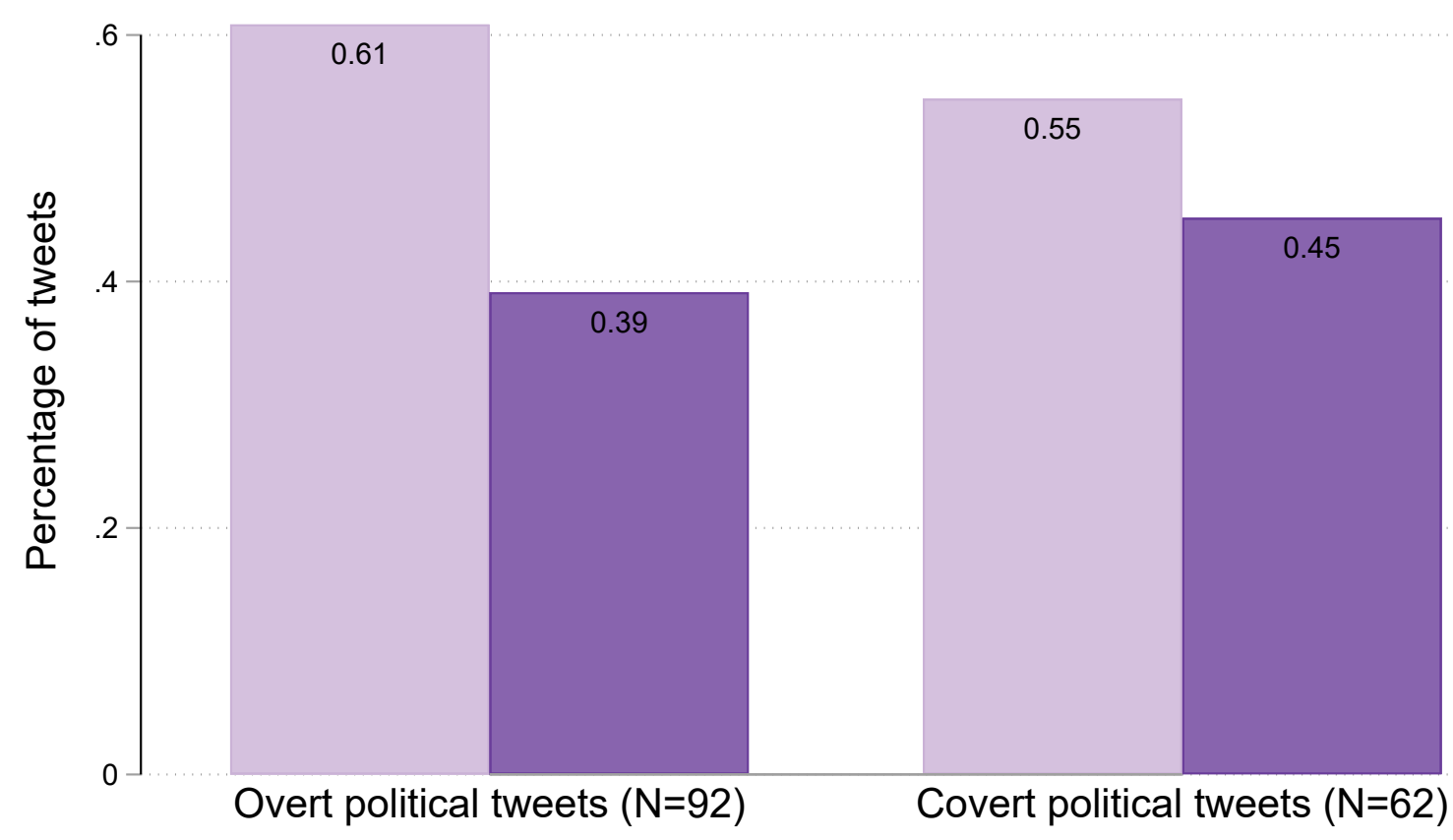

Figure S5: Proportion of overt and covert tweets in each type of Twitter account network.

Although the difference in the relative use of covert signaling in homogeneous and heterogeneous networks on Twitter was in the predicted direction, it was relatively small. This is reasonable, given the small sample of selected covert and overt tweets as well as the vast number of factors that influence online communication in a public forum such as Twitter. We hope future research pursues this line of inquiry and develops a wider data collection 
process and measures of covertness to formally compare the use of covert political identity signaling on Twitter. 


\section{Behavioral Experiment}

Below is a list of recent tweets downloaded directly from the web in the last month. Please rate each tweet regarding how
much you dislike or like it.

Figure S6: First part of experiment: rating of each of the 80 tweets selected as covert and overt from both co- and cross-partisan sources. 


Cross-partisan audience ( $\mathrm{N}=\mathbf{2 4 3}$ )
PLEASE READ THE INSTRUCTIONS CAREFULLY, THE
TEXT IN RED WILL CHANGE FOR EACH PAGE.
You are now interacting with ten other people who are
also participating in this study.
[Size group 1] described themselves as being on the
left of the political spectrum, and [size group 2 ]
described themselves as being on the right.
For each person who likes most of the tweets you
share, you will receive an additional 1 cent.
For each person who dislikes most of the tweets you
share, you will lose [cost of dislike].
In other words, for this page, if all ten people like most
of the tweets you share, you will receive additional 10
cents. If all ten people dislike most of the tweets you
share, you will lose [total possible cost].

Co-partisan audience N=235
PLEASE READ THE INSTRUCTIONS CAREFULLY, THE
TEXT IN RED WILL CHANGE FOR EACH PAGE.
You are now interacting with ten other people who are
also participating in this study.
[Size group 1] described themselves as being on the
far left (right) of the political spectrum, and [Size
group 2] described themselves as being mainstream
left (right).
For each person who likes most of the tweets you
share, you will receive an additional 1 cent.
For each person who dislikes most of the tweets you
share, you will lose [cost of dislike].
In other words, for this page, if all ten people like most
of the tweets you share, you will receive additional 10
cents. If all ten people dislike most of the tweets you
share, you will [total possible cost].

\section{Each participant receives 8 different combinations of group sizes and costs of dislike:}

1) Size group 1 (and group 2): 1(9), 4(6), 6(4), 9(1)

2) Cost of dislike (and total possible cost): 0.5 cent each (5 cents total) or 1 cent each (10 cents total).

Figure S7: Second part of experiment: material and conditions. Text in red brackets was replaced by different values for group sizes and costs of dislikes listed in the bottom box. 
(a)

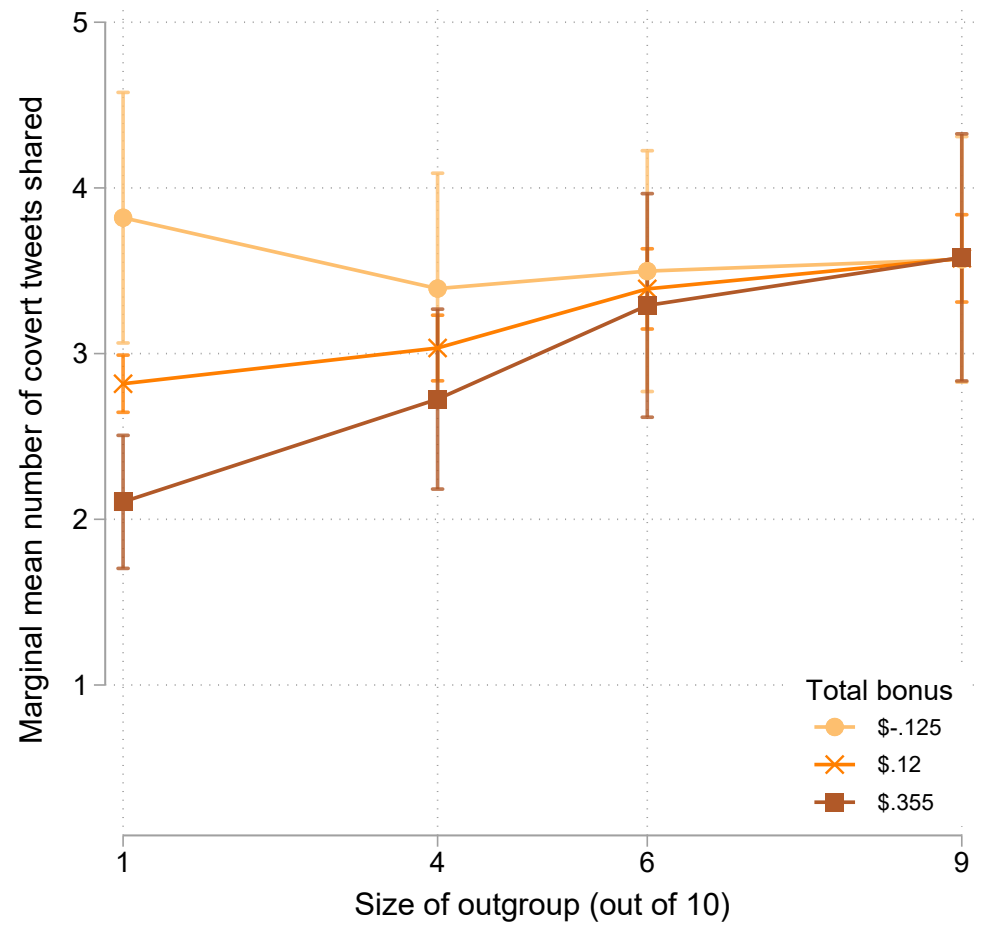

(b)

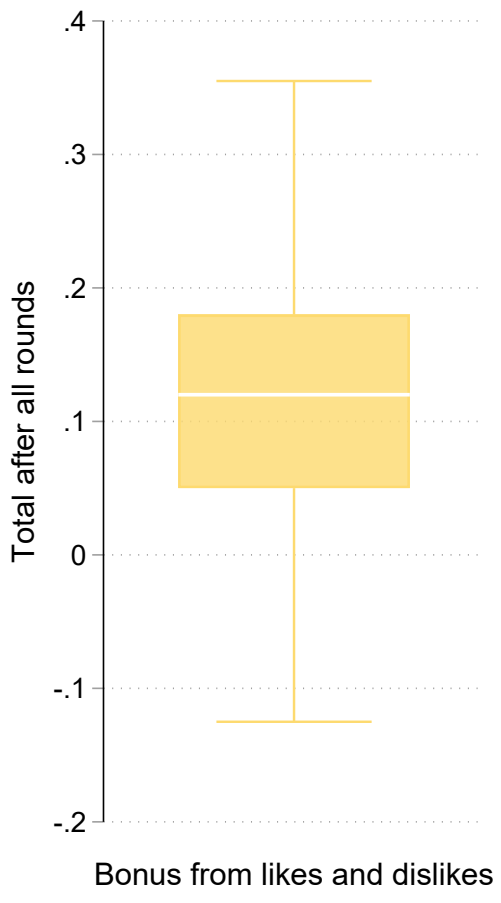

Figure S8: Bonuses received at the end of the behavioral experiment for participants with cross-partisan audiences, $\mathrm{N}=243$. Average predictive margins for the use of covert tweets with 95\% confidence intervals by total payoff (a) and sample distribution of total bonuses received at the end of the eight experimental rounds (b). Estimates are from multilevel Poisson models with random intercepts by individuals over experimental conditions, averaging predicted number of tweets shared across sample values for number of tweets shared, political leaning, age, gender, race, and education. 


\section{Power analysis}

For the behavioral experiment, we used two independent samples (co-partisan and crosspartisan comparisons) and four groups of raters (left radical, left moderate, right moderate, and right radical). With our budget and time to share tweets, we estimated that we could get 60 individuals per category (a total of 480 participants).

We calculated the power for detecting a linear increase in the total number of covert tweets shared over the outgroup size with one predictor (comparison), another within effect (cost), two independent samples (cross-partisan raters and co-partisan raters), and controlling for the total number of tweets shared, for a total sample size of 480 participants.

For the cross-partisan high-cost condition, we assumed a conservative increase in the average number of covert tweets shared for each additional outgroup audience member, from zero covert tweets when there are no outgroup members to one covert tweet when there are only outgroup members (see estimates for our actual outgroup sizes in Table S7). We also assumed that for the low-cost condition (where dislikes were half as costly), the increase would be a third less than in the high-cost condition. We also assumed that participants in the co-partisan condition would generally share half of the number of covert tweets compared to the cross-partisan condition, but the effect of outgroup size would not be different than in the cross-partisan condition.

We assumed the standard deviation for the total number of covert tweets shared would be around two tweets and the standard deviation to increase over outgroup size and to be higher for the low-cost option. We expect the total number of tweets to have a standard deviation of eight and to be highly correlated with the total number of covert tweets shared, although decreasing over time.

Table S7: Add caption

\begin{tabular}{rrrrr}
\hline & \multicolumn{2}{c}{ cross-partisan } & \multicolumn{2}{c}{ co-partisan } \\
outgroup size & high-cost & low-cost & high-cost & low-cost \\
\hline $\mathbf{1}$ & 0.10 & 0.10 & 0.05 & 0.05 \\
$\mathbf{4}$ & 0.40 & 0.33 & 0.20 & 0.16 \\
$\mathbf{6}$ & 0.60 & 0.48 & 0.30 & 0.24 \\
$\mathbf{9}$ & 0.90 & 0.70 & 0.45 & 0.35 \\
\hline
\end{tabular}

Using the statistical software GLIMMPSE (Kreidler et al., 2013), , we used the LEAR model to describe correlations which monotonically decrease with distance between the outgroups and costs. Using the Hotelling Lawley Trace test, we find that we have at least a $96.2 \%$ chance of detecting the effect of outgroup size with a sample size of 60 per group with a 0.01 error rate. For the same sample and error rate, we have a $99.4 \%$ chance of detecting an interaction between cost and outgroup size. 


\section{Sample descriptives}
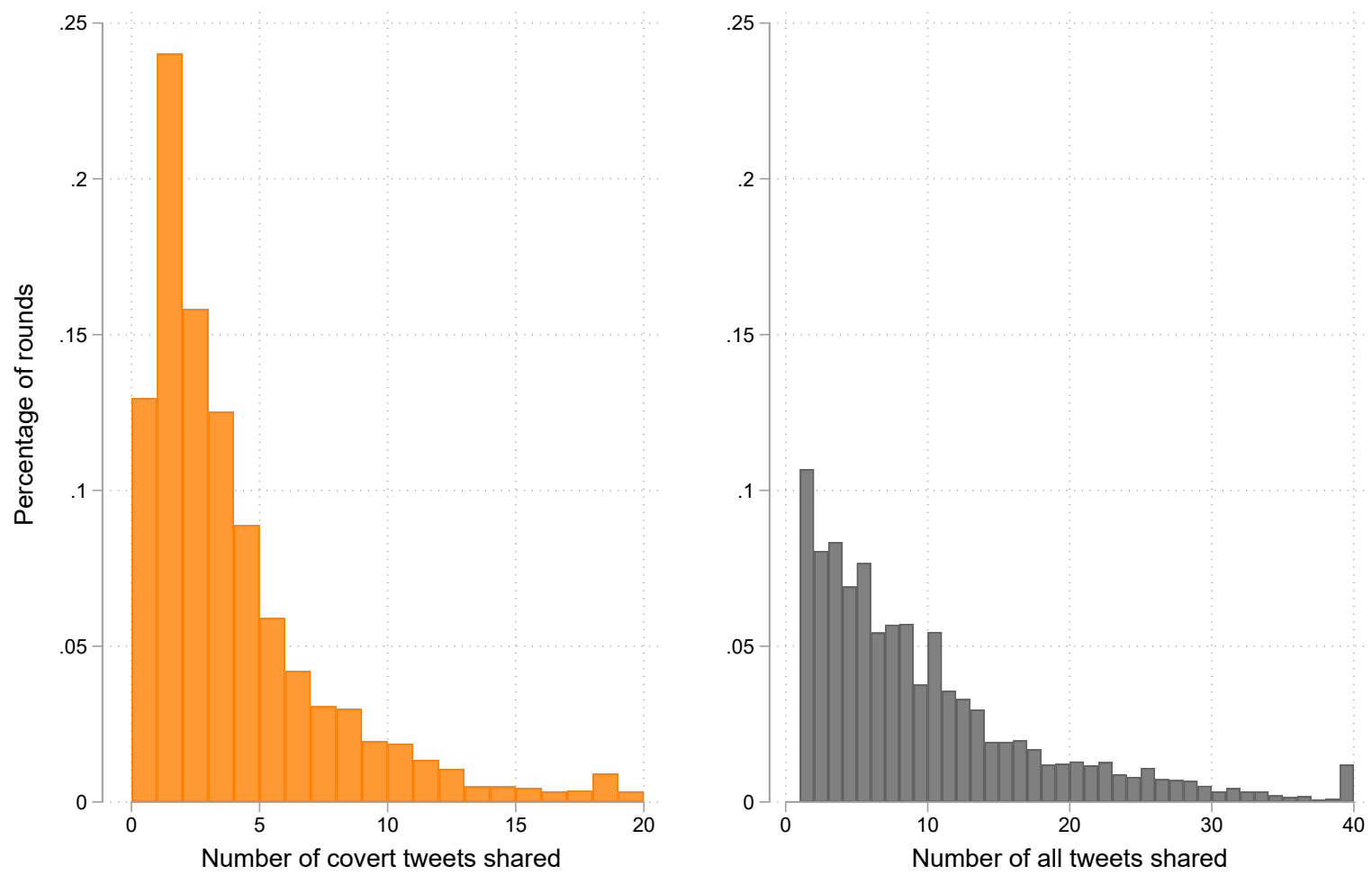

Figure S9: Proportion of rounds by the number of covert and total tweets shared.

Table S8: Sample Descriptive Statistics $(\mathrm{N}=481)$

\begin{tabular}{lrrrrrrrr}
\hline & \multicolumn{2}{c}{ Far left } & \multicolumn{3}{c}{ Mainstream left } & \multicolumn{2}{c}{ Mainstream right } & \multicolumn{2}{c}{ Far right } \\
& Mean/Prop. & SD & Mean/Prop. & SD & Mean/Prop. & SD & Mean/Prop. & SD \\
\hline \hline Age & 34.14 & 10.90 & 42.21 & 13.32 & 40.02 & 10.44 & 44.66 & 13.38 \\
Women & .51 & & .43 & .59 & & .32 & \\
Non-white & .23 & & .18 & .12 & .09 & \\
College educated & .63 & & .59 & .57 & .62 & \\
\hline
\end{tabular}




\section{Statistical model}

To compare the effect of different experimental conditions and individual-level characteristics, we conducted a generalized mixed-effects Poisson count model on the number of covert tweets shared per round with each outgroup experimental condition nested within individuals. An analysis of the linear mixed-effects model showed enough variation between individuals to warrant random intercepts for each individual (intra-class correlation between 0.304 and 0.775 across model and significant Breusch-Pagan test for cluster-level variation $\left(583<\chi^{2}<\right.$ 3973). Given that we want to analyze the number of all tweets and covert tweets shared, we approximate our outcome distribution using a Poisson distribution. We compared the addition of outgroup size as a continuous or categorical variable and found the latter to be a better fit. The resulting point estimates are in Table S9.

Table S9: Poisson mixed model estimates on count of covert ( $a$ and b) and total (c and d) tweets shared in each round in the co-partisan (a and c) and cross-partisan (b and d) conditions. Estimates used for Figure 5. Standard errors in parenthesis.

\begin{tabular}{|c|c|c|c|c|}
\hline & (a) & (b) & (c) & (d) \\
\hline \multicolumn{5}{|l|}{$\begin{array}{l}\text { Size of outgroup } \\
(\text { ref }=1 \text { out of } 10)\end{array}$} \\
\hline 4 out of 10 & $\begin{array}{l}0.028 \\
(0.048)\end{array}$ & $\begin{array}{l}0.058 \\
(0.049)\end{array}$ & $\begin{array}{l}-0.028 \\
(0.028)\end{array}$ & $\begin{array}{l}-0.217 \\
(0.030)\end{array}$ \\
\hline 6 out of 10 & 0.011 & 0.137 & -0.035 & -0.494 \\
\hline 9 out of 10 & 0.030 & 0.189 & 0.002 & -0.644 \\
\hline High cost $($ ref $=$ low cost $)$ & $\begin{array}{l}(0.047) \\
0.037 \\
(0.048)\end{array}$ & $\begin{array}{l}(0.054) \\
-0.039 \\
(0.047)\end{array}$ & $\begin{array}{l}(0.027) \\
-0.036 \\
(0.028)\end{array}$ & $\begin{array}{l}(0.034) \\
0.026 \\
(0.028)\end{array}$ \\
\hline \multicolumn{5}{|l|}{$\begin{array}{l}\text { Size of outgroup } * \text { cost } \\
(\text { ref }=1 \text { out of } 10 \text { and low cost })\end{array}$} \\
\hline 4 out of $10 \&$ high cost & $\begin{array}{l}-0.010 \\
(0.068)\end{array}$ & $\begin{array}{l}0.029 \\
(0.069)\end{array}$ & $\begin{array}{l}0.027 \\
(0.039)\end{array}$ & $\begin{array}{l}-0.048 \\
(0.042)\end{array}$ \\
\hline 6 out of $10 \&$ high cost & $\begin{array}{l}-0.016 \\
(0.068)\end{array}$ & $\begin{array}{l}0.084 \\
(0.072)\end{array}$ & $\begin{array}{l}0.039 \\
(0.039)\end{array}$ & -0.056 \\
\hline 9 out of $10 \&$ high cost & $\begin{array}{l}-0.062 \\
(0.067)\end{array}$ & $\begin{array}{l}0.079 \\
(0.073)\end{array}$ & $\begin{array}{l}0.028 \\
(0.039)\end{array}$ & $\begin{array}{l}-0.052 \\
(0.048)\end{array}$ \\
\hline Total number of tweets shared & $\begin{array}{l}0.081 \\
(0.002)\end{array}$ & $\begin{array}{l}0.080 \\
(0.002)\end{array}$ & & \\
\hline Right participants (ref=left participants) & $\begin{array}{l}0.015 \\
(0.055)\end{array}$ & $\begin{array}{l}-0.003 \\
(0.049)\end{array}$ & $\begin{array}{l}-0.051 \\
(0.098)\end{array}$ & $\begin{array}{l}-0.067 \\
(0.098)\end{array}$ \\
\hline \multicolumn{5}{|l|}{ Individual-level controls } \\
\hline & $(0.002)$ & $(0.002)$ & $(0.004)$ & $(0.004)$ \\
\hline Women $(\mathrm{ref}=\mathrm{men})$ & $\begin{array}{l}-0.130 \\
(0.055)\end{array}$ & $\begin{array}{l}-0.058 \\
(0.049)\end{array}$ & $\begin{array}{l}-0.122 \\
(0.097)\end{array}$ & $\begin{array}{l}-0.099 \\
(0.097)\end{array}$ \\
\hline White (ref=non-white) & $\begin{array}{l}-0.024 \\
(0.080)\end{array}$ & $\begin{array}{l}0.009 \\
(0.064)\end{array}$ & $\begin{array}{l}0.155 \\
(0.146)\end{array}$ & $\begin{array}{l}0.113 \\
(0.129)\end{array}$ \\
\hline College educated $(\mathrm{ref}=$ no college $)$ & $\begin{array}{l}0.044 \\
(0.056)\end{array}$ & $\begin{array}{l}-0.003 \\
(0.048)\end{array}$ & $\begin{array}{l}-0.072 \\
(0.100)\end{array}$ & $\begin{array}{l}-0.204 \\
(0.097)\end{array}$ \\
\hline Constant & 0.014 & 0.310 & 2.219 & 2.206 \\
\hline Individual-level variance & $\begin{array}{l}(0.116) \\
0.118 \\
(0.018)\end{array}$ & $\begin{array}{l}(0.099) \\
0.082 \\
(0.014)\end{array}$ & $\begin{array}{l}(0.196) \\
0.530 \\
(0.052)\end{array}$ & $\begin{array}{l}(0.183) \\
0.518 \\
(0.051)\end{array}$ \\
\hline
\end{tabular}

In Table S10 we present the linear mixed model of the number of covert tweets shared in co-partisan and cross-partisan conditions centered by group. The main results are sub- 
Table S10: Linear mixed model estimates on count of covert tweets shared in each round in the co-partisan (a) and cross-partisan (b) conditions with covariance matrices centered by group. Standard error in parenthesis.

(a) (b)

\begin{tabular}{|c|c|c|}
\hline \multicolumn{3}{|l|}{$\begin{array}{l}\text { Size of outgroup } \\
(r e f=1 \text { out of } 10)\end{array}$} \\
\hline 4 out of 10 & $\begin{array}{l}0.007 \\
(0.093)\end{array}$ & $\begin{array}{l}0.320 \\
(0.103)\end{array}$ \\
\hline 6 out of 10 & $\begin{array}{l}0.021 \\
(0.093)\end{array}$ & $\begin{array}{l}0.658 \\
(0.104)\end{array}$ \\
\hline 9 out of 10 & $\begin{array}{l}0.078 \\
(0.093)\end{array}$ & $\begin{array}{l}0.869 \\
(0.105)\end{array}$ \\
\hline High cost $($ ref $=$ low-cost $)$ & $\begin{array}{l}0.112 \\
(0.093)\end{array}$ & $\begin{array}{l}-0.007 \\
(0.103)\end{array}$ \\
\hline \multicolumn{3}{|l|}{$\begin{array}{l}\text { Size of outgroup } * \text { cost } \\
\text { (ref=1 out of } 10 \text { and low-cost })\end{array}$} \\
\hline 4 out of $10 \&$ high-cost & $\begin{array}{l}-0.060 \\
(0.131)\end{array}$ & $\begin{array}{l}-0.002 \\
(0.145)\end{array}$ \\
\hline 6 out of $10 \&$ high-cost & $\begin{array}{l}-0.064 \\
(0.131)\end{array}$ & $\begin{array}{l}0.039 \\
(0.145)\end{array}$ \\
\hline 9 out of $10 \&$ high-cost & $\begin{array}{l}-0.195 \\
(0.131)\end{array}$ & $\begin{array}{l}0.118 \\
(0.145)\end{array}$ \\
\hline Total number of tweets shared & $\begin{array}{l}0.423 \\
(0.005)\end{array}$ & $\begin{array}{l}0.407 \\
(0.005)\end{array}$ \\
\hline Right participants (ref $=$ left participants) & $\begin{array}{l}0.305^{*} \\
(0.142)\end{array}$ & $\begin{array}{l}-0.067 \\
(0.112)\end{array}$ \\
\hline \multicolumn{3}{|l|}{ Individual-level controls } \\
\hline Age & $\begin{array}{l}0.003 \\
(0.006)\end{array}$ & $\begin{array}{l}-0.008 \\
(0.004)\end{array}$ \\
\hline Women $(\mathrm{ref}=\mathrm{men})$ & $\begin{array}{l}-0.406 \\
(0.141)\end{array}$ & $\begin{array}{l}-0.239 \\
(0.110)\end{array}$ \\
\hline White (ref=non-white) & $\begin{array}{l}0.168 \\
(0.213)\end{array}$ & $\begin{array}{l}-0.223 \\
(0.146)\end{array}$ \\
\hline College educated $(\mathrm{ref}=$ no college $)$ & $\begin{array}{l}0.326 \\
(0.146)\end{array}$ & $\begin{array}{l}0.190 \\
(0.111)\end{array}$ \\
\hline Constant & $\begin{array}{l}-1.227 \\
(0.296)\end{array}$ & $\begin{array}{l}-0.081 \\
(0.223)\end{array}$ \\
\hline Individual-level variance & $\begin{array}{l}1.031 \\
(0.053)\end{array}$ & $\begin{array}{l}0.559 \\
(0.033)\end{array}$ \\
\hline \multicolumn{3}{|l|}{ Group-level variance } \\
\hline Far left & $\begin{array}{l}1.088 \\
(0.039)\end{array}$ & $\begin{array}{l}1.058 \\
(0.036)\end{array}$ \\
\hline Mainstream left & $\begin{array}{l}1.025 \\
(0.050)\end{array}$ & $\begin{array}{l}1.422 \\
(0.048)\end{array}$ \\
\hline Mainstream right & $\begin{array}{l}0.887 \\
(0.049)\end{array}$ & $\begin{array}{l}1.632 \\
(0.049)\end{array}$ \\
\hline Far right & $\begin{array}{l}1.170 \\
(0.051)\end{array}$ & $\begin{array}{l}1.1775 \\
(0.048)\end{array}$ \\
\hline
\end{tabular}


stantively similar to those in Table S9. However, the linear models enabled the estimation of different covariance matrices for each political group. The variance of the residuals shows that in the co-partisan condition (a), participants from the far left and far right had a larger variance than those in the mainstream. However, in the cross-partisan condition (b), participants from the far left and far right had lower variance than those who were more mainstream.

\section{References}

Kreidler, S., Muller, K., Grunwald, G., Ringham, B., Coker-Dukowitz, Z., Sakhadeo, U., Barón, A., and DH, D. G. (2013). Glimmpse: online power computation for linear models with and without a baseline covariate. Journal of Statistical Software, 54(10).

Levay, K. E., Freese, J., and Druckman, J. N. (2016). The demographic and political composition of mechanical turk samples. Sage Open, 6(1):1-17. 